\title{
Preparation of Fluoroalkyl End-Capped Oligomers/Hexagonal Boron Nitride Nanocomposites Possessing No Weight Loss Behavior in Nanocomposites Even after Calcination at $800^{\circ} \mathrm{C}$
}

\author{
Jittraporn Saengkaew1, Takahumi Ogasawara1, Katsumi Yamashita1, Suwadee Kongparakul2, \\ Hideo Sawada ${ }^{*}$
}

${ }^{1}$ Department of Frontier Materials Chemistry, Graduate School of Science and Technology, Hirosaki University, Hirosaki, Japan ${ }^{2}$ Department of Chemistry, Faculty of Science and Technology, Thammasat University, Pathumthani, Thailand

Email: *hideosaw@hirosaki-u.ac.jp

How to cite this paper: Saengkaew, J., Ogasawara, T., Yamashita, K., Kongparakul, S. and Sawada, H. (2019) Preparation of Fluoroalkyl End-Capped Oligomers/Hexagonal Boron Nitride Nanocomposites Possessing No Weight Loss Behavior in Nanocomposites Even after Calcination at $800^{\circ} \mathrm{C}$. Open Journal of Composite Materials, 9, 72-98.

https://doi.org/10.4236/ojcm.2019.92004

Received: February 5, 2019

Accepted: March 11, 2019

Published: March 14, 2019

Copyright $\odot 2019$ by author(s) and Scientific Research Publishing Inc. This work is licensed under the Creative Commons Attribution International License (CC BY 4.0).

http://creativecommons.org/licenses/by/4.0/

c) (i) Open Access

\begin{abstract}
Fluoroalkyl end-capped acrylic acid oligomer $\left[\mathrm{R}_{\mathrm{F}}-(\mathrm{ACA})_{n}-\mathrm{R}_{\mathrm{F}}\right] /$ hexagonal boron nitride $(\mathrm{h}-\mathrm{BN})$ nanocomposites $\left[\mathrm{R}_{\mathrm{F}}-(\mathrm{ACA})_{n}-\mathrm{R}_{\mathrm{F}} / \mathrm{h}-\mathrm{BN}\right]$ were prepared by reaction of the corresponding oligomer with h-BN nanoparticles (mean diameter: $50 \mathrm{~nm}$ ) under non-catalytic or alkaline conditions, respectively. Fluoroalkyl end-capped $N, N$-dimethylacrylamide oligomer/h-BN nanocomposites $\left[\mathrm{R}_{\mathrm{F}}-(\mathrm{DMAA})_{n}-\mathrm{R}_{\mathrm{F}} / \mathrm{h}-\mathrm{BN}\right]$ were also obtained under similar conditions. It was demonstrated that $\mathrm{R}_{\mathrm{F}}-(\mathrm{ACA})_{n}-\mathrm{R}_{\mathrm{F}} / \mathrm{h}-\mathrm{BN}$ nanocomposites, which were prepared under alkaline conditions, afforded a clear weight loss in proportion to the contents of the oligomer in the composites after calcination at $800^{\circ} \mathrm{C}$; however, the non-catalytic conditions enabled the $\mathrm{R}_{\mathrm{F}}-(\mathrm{ACA})_{n}-\mathrm{R}_{\mathrm{F}} / \mathrm{h}-\mathrm{BN}$ nanocomposite to give no weight loss behavior corresponding to the contents of the oligomer even after calcination. In fact, it was demonstrated that the $\mathrm{R}_{\mathrm{F}}-(\mathrm{ACA})_{n}-\mathrm{R}_{\mathrm{F}} / \mathrm{h}-\mathrm{BN}$ nanocomposites possessing a clear weight loss property could afford the fluorescent peak around $370 \mathrm{~nm}$ related to $\mathrm{h}-\mathrm{BN}$ in the composites; however, the same fluorescent intensity of this nanocomposite after calcination at $800^{\circ} \mathrm{C}$ as that of the original h-BN was observed, indicating that this nanocomposite could give a clear weigh loss behavior corresponding to the content of the oligomer during the calcination process. In contrast, the $\mathrm{R}_{\mathrm{F}}-(\mathrm{ACA})_{n}-\mathrm{R}_{\mathrm{F}} / \mathrm{h}-\mathrm{BN}$ nanocomposites possessing no weigh loss behavior were found to exhibit the similar fluorescent intensity before and even after calcination at $800^{\circ} \mathrm{C}$, suggesting that the corresponding nanocomposites could provide no weight loss ability corresponding to the contents of
\end{abstract}


the oligomer in the composites even after calcination. Similarly, $\mathrm{R}_{\mathrm{F}^{-}}$ $(\mathrm{DMAA})_{n}-\mathrm{R}_{\mathrm{F}} / \mathrm{h}-\mathrm{BN}$ nanocomposites, which were prepared under non-catalytic or alkaline conditions, were found to provide no weight loss corresponding to the contents of the oligomer even after calcination, respectively. These fluorinated h-BN nanocomposites were applied to the surface modification of PMMA [poly(methyl methacrylate)] to exhibit an oleophobic property on the modified PMMA surface. $\mathrm{R}_{\mathrm{F}}-(\mathrm{ACA})_{n}-\mathrm{R}_{\mathrm{F}} / \mathrm{h}-\mathrm{BN}$ nanocomposites possessing a clear weight loss behavior, whose composites were calcinated at $800^{\circ} \mathrm{C}$, afforded not oleophobic but oleophilic property on the modified PMMA surface, quite similar to that of the pristine PMMA film surface; however, more interestingly, we found that $\mathrm{R}_{\mathrm{F}}-(\mathrm{ACA})_{n}-\mathrm{R}_{\mathrm{F}} /$ and $\mathrm{R}_{\mathrm{F}}-(\mathrm{DMAA})_{n}{ }^{-}$ $\mathrm{R}_{\mathrm{F}} / \mathrm{h}-\mathrm{BN}$ nanocomposites possessing no weight loss characteristic, whose composites were calcined at $800^{\circ} \mathrm{C}$, could supply a good oleophobic property related to the fluoroalkyl segments in the composites on the modified PMMA surfaces, respectively.

\section{Keywords}

Fluorinated Oligomer, Hexagonal Boron Nitride, Nanocomposite, Thermal Stability, No Weight Loss, Calcination, Surface Modification, Oleophobicity, Fluorecence Spectra, PMMA

\section{Introduction}

Inorganic/organic composites have attracted much attention owing to their exhibiting a large variety of extraordinary characteristics derived from the synergism among the properties of each individual material [1]. A great interest has also been focused on the studies for the hybrid materials based on the composite reactions of organic polymers with inorganic nanoparticles [2] [3]. In these inorganic guest molecules, hexagonal boron nitride (h-BN) nanoparticle is especially among the most promising inorganic nanomaterials in recent years [4]-[15]. Their unique properties, including high mechanical stiffness, excellent thermal conductivity, excellent dimension stability, desirably low dielectric loss and constant, high temperature stability, high melting point, high corrosion resistance, and chemical inertness, suggest many potential applications in numerous fields [16]-[43]. Therefore, there have been numerous reports on the development of the h-BN/organic polymer composites materials possessing such unique properties imparted by $\mathrm{h}-\mathrm{BN}$, especially excellent thermal conductivity [16]-[43], because h-BN can endow organic polymers with increased thermal conductivity, decreased coefficient of thermal expansion, and decreased dielectric loss, which cannot be achieved by the other inorganic fillers such as aluminum nitride and silicon carbide [44] [45]. From the developmental viewpoints of new fluorinated functional materials, it is of particular interest to develop the novel fluorinated h-BN nanocomposites; however, such studies have been very limited except for some reports on the surface modification of 
h-BN with perfluorooctyl-triethoxysilane [46] [47], perfluorobutyric acid [48], poly (tetrafluoroethylene) [49], and preparation of poly(vinylidene fluoride)/boron nitride nanosheet composite films [50]. Heretofore, we have been comprehensively studying on the synthesis and applications on the ABA triblock-type two fluoroalkyl end-capped oligomers $\left(\mathrm{R}_{\mathrm{F}}-(\mathrm{M})_{n}-\mathrm{R}_{\mathrm{F}} ; \mathrm{R}_{\mathrm{F}}=\right.$ fluoroalkyl groups; $\mathrm{M}=$ radical polymerizable hydrocarbon monomers) [51] [52] [53]. These fluoroalkyl end-capped oligomers can form the nanometer size-controlled self-assembled molecular aggregates through the aggregation of terminal fluoroalkyl segments in aqueous and organic media [54] [55] [56] [57]. These fluorinated oligomeric aggregates can interact with a variety of inorganic guest molecules such as silica, titanium oxide, hydroxyapatite, gold, silver, copper, palladium, zinc oxide, magnetite, calcium carbonate, calcium silicide, magnesium carbonate, magnesium oxide, and talc to afford the corresponding fluorinated oligomeric aggregates/guest molecules nanocomposites [58]-[79]. In fact, fluoroalkyl end-capped oligomeric nanocomposites-encapsulated gold nanoparticles can provide linear arrays of these fluorinated nanocomposite particles to afford the extremely red-shifted plasmon absorption band at around $960 \mathrm{~nm}$ [73]. Anatase titanium oxide nanoparticles $\left(a n-\mathrm{TiO}_{2}\right)$ can be encapsulated into fluoroalkyl end-capped vinyltrimethoxysilane oligomeric nanoparticle cores to provide the corresponding fluorinated oligomer/an- $\mathrm{TiO}_{2}$ nanocomposites, and crystalline structure of $a n-\mathrm{TiO}_{2}$ in the nanocomposites was found to keep completely its structure without phase transformation to rutile even after calcination at $1000^{\circ} \mathrm{C}$, although crystalline structure of the original $a n-\mathrm{TiO}_{2}$ nanoparticles suffered a complete phase transformation to the rutile under similar conditions [80] [81] [82]. Thus, it is of particular interest to explore novel fluoroalkyl end-capped oligomeric nanocomposites by using h-BN inorganic fine particles as the guest molecule. Here, we report on the preparation and properties of novel fluoroalkyl end-capped oligomeric nanocomposites by using h-BN nanoparticles. Especially, we have found that fluoroalkyl end-capped acrylic acid oligomer and $\mathrm{N}, \mathrm{N}$-dimethylacrylamide oligomer can interact with h-BN nanoparticles under non-catalytic or alkaline conditions to afford the corresponding oligomers/h-BN nanocomposites, respectively. Interestingly, the fluorinated oligomers/h-BN nanocomposites under non-catalytic conditions were found to give no weight loss behavior corresponding to the contents of oligomers in the nanocomposites even after calcination at $800^{\circ} \mathrm{C}$. More interestingly, we have observed the similar fluorescent intensity related to the presence of $\mathrm{h}-\mathrm{BN}$ in the $\mathrm{R}_{\mathrm{F}}-(\mathrm{ACA})_{n}-\mathrm{R}_{\mathrm{F}} / \mathrm{h}-\mathrm{BN}$ nanocomposites possessing no weigh loss behavior before and even after calcination at $800^{\circ} \mathrm{C}$. Fluoroalkylend-capped $\mathrm{N}, \mathrm{N}$-dimethylacrylamide oligomer/h-BN nanocomposites, which were prepared under alkaline conditions, also afforded the similar no weight loss characteristic even after calcination. These results with the application to the surface modification of traditional organic polymers will be described in this article. 


\section{Experimental}

\subsection{Measurements}

Molecular weights of $\mathrm{R}_{\mathrm{F}}-(\mathrm{ACA})_{n}-\mathrm{R}_{\mathrm{F}}$ oligomer and $\mathrm{R}_{\mathrm{F}}-(\mathrm{DMAA})_{n}-\mathrm{R}_{\mathrm{F}}$ oligomer were measured using a Shodex DS-4 (pump) and Shodex RI-71 (detecter) gel permeation chromatography (Tokyo, Japan) calibrated with polystyrene standard using tetrahydrofuran (THF) as the eluent. Thermal analyses were recorded by raising the temperature around $800^{\circ} \mathrm{C}$ (the heating rate: $10^{\circ} \mathrm{C} / \mathrm{min}$ ) under atmospheric conditions by the use of Bruker axs TG-DTA2000SA differential thermobalance (Kanagawa, Japan). Size (number-average diameter (average hydrodynamic diameter)) of nanocomposites was measured by using Otsuka Electronics DLS-7000 HL (Tokyo, Japan). Field emission scanning electron micrographs (FE-SEM) and energy dispersive X-ray (EDX) spectra were recorded by means of JEOL JSM-7000F (Tokyo, Japan). X-ray diffraction (XRD) measurements were performed by the use of MiniFlex 600 (Tokyo, Japan). Contact angles were measured using a Kyowa Interface Science Drop Master 300 (Saitama, Japan). Fluorescent spectra of the parent h-BN particles and the nanocomposites were obtained using a Shimadzu RF-5300 PC spectrophotometer.

\subsection{Materials}

h-BN nanoparticles (average particle size: $50 \mathrm{~nm}$ ) were kindly supplied from Maruka Corp. Ltd. (Gifu, Japan). Acrylic acid and $N, N$-dimethylacrylamide were used as received from Toagosei Co. (Tokyo, Japan) and KJ Chemicals Co., Ltd. (Tokyo, Japan), respectively.

Fluoroalkyl end-capped acrylic acid oligomer $(\mathrm{Mn}=3000)$ and $N, N$-dimethylacrylamide oligomer $(\mathrm{Mn}=1690)$ were prepared according to our previously reported methods, respectively [83] [84].

1) Preparation of fluoroalkyl end-capped acrylic acid oligomer/h-BN nanocomposites $\left[\mathrm{R}_{\mathrm{F}}-(\mathrm{ACA})_{n}-\mathrm{R}_{\mathrm{F}} / \mathrm{h}-\mathrm{BN}\right]$

A typical procedure for the preparation of $\mathrm{R}_{\mathrm{F}}-(\mathrm{ACA})_{n}-\mathrm{R}_{\mathrm{F}} / \mathrm{h}-\mathrm{BN}$ nanocomposites is as follows: To methanol solution $(12 \mathrm{ml})$ containing fluoroalkyl end-capped acrylic acid oligomer $\left[\mathrm{R}_{\mathrm{F}}-\left(\mathrm{CH}_{2} \mathrm{CHCOOH}\right)_{n}-\mathrm{R}_{\mathrm{F}} ; \mathrm{R}_{\mathrm{F}}=\mathrm{CFCF}_{3} \mathrm{OC}_{3} \mathrm{~F}_{7}\right.$ : $\mathrm{R}_{\mathrm{F}}-(\mathrm{ACA})_{n}-\mathrm{R}_{\mathrm{F}}$ ] (100 mg) and h-BN nanoparticle powders $(100 \mathrm{mg})$ was added $25 \%$ aqueous ammonia solution $(5 \mathrm{ml})$. The mixture was stirred with a magnetic stirring bar at room temperature for $5 \mathrm{~h}$. After the solvent was evaporated off, methanol was added to the obtained crude products. The methanol suspension thus obtained was stirred with magnetic stirring bar at room temperature for 1 day, and then was centrifuged for $30 \mathrm{~min}$. The expected fluorinated oligomer/h-BN nanocomposites were easily separated from the methanol solution. After centrifugal separation of this solution, the obtained product was dried in vacuum at $50^{\circ} \mathrm{C}$ for 1 day to produce the fluorinated composite white colored powders $(128 \mathrm{mg})$. In addition, the obtained supernatant solution was evaporated off under reduced pressure, and then dried in vacuum at $50^{\circ} \mathrm{C}$ for 1 day to isolate the product $(14 \mathrm{mg})$. Similarly, $\mathrm{R}_{\mathrm{F}}-(\mathrm{ACA})_{n}-\mathrm{R}_{\mathrm{F}} / \mathrm{h}-\mathrm{BN}$ nanocomposites 
were prepared under non-catalytic conditions (no use of ammonia). Fluoroalkylend-capped $N, N$-dimethylacrylamide oligomer/h-BN nanocomposites were also prepared under similar conditions.

2) Preparation of modified PMMA films treated with the

\section{$\mathrm{R}_{\mathrm{F}}-(\mathrm{ACA})_{n}-\mathrm{R}_{\mathrm{F}} / \mathrm{h}-\mathrm{BN}$ nanocomposites}

The modified PMMA films were prepared by casting solutions of 1,2-dichloroethane $(25 \mathrm{ml})$ containing poly(methyl methacrylate) (PMMA: $990 \mathrm{mg}$ ) and the $\mathrm{R}_{\mathrm{F}}-(\mathrm{ACA})_{n}-\mathrm{R}_{\mathrm{F}} / \mathrm{h}-\mathrm{BN}$ nanocomposites $(10 \mathrm{mg})$ on glass plate. The solvent was evaporated at room temperature and the films formed peeled off and dried at $50^{\circ} \mathrm{C}$ for $24 \mathrm{~h}$ under vacuum to afford the transparent colorless modified PMMA films. The modified PMMA films treated with the $\mathrm{R}_{\mathrm{F}}-(\mathrm{ACA})_{n}-\mathrm{R}_{\mathrm{F}} / \mathrm{h}-\mathrm{BN}$ nanocomposites after calcination at $800^{\circ} \mathrm{C}$ and the $\mathrm{R}_{\mathrm{F}}-(\mathrm{DMAA})_{n}-\mathrm{R}_{\mathrm{F}} / \mathrm{h}-\mathrm{BN}$ nanocomposites before and after calcination at $800^{\circ} \mathrm{C}$ were prepared under similar conditions.

\section{Results and Discussion}

Fluoroalkyl end-capped acrylic acid oligomer $\left[\mathrm{R}_{\mathrm{F}}-(\mathrm{ACA})_{n}-\mathrm{R}_{\mathrm{F}}\right]$ was found to interact with hexagonal boron nitride (h-BN) nanoparticles under non-catalytic or alkaline conditions at room temperature to afford the corresponding $\mathrm{R}_{\mathrm{F}}-(\mathrm{ACA})_{n}-\mathrm{R}_{\mathrm{F}} / \mathrm{h}-\mathrm{BN}$ composites. Fluoroalkyl end-capped

$\mathrm{N}, \mathrm{N}$-dimethylacrylamide oligomer/h-BN composites were also prepared under similar conditions. The results are shown in Scheme 1 and Table 1.

As shown in Scheme 1 and Table 1 , the expected $\mathrm{R}_{\mathrm{F}}-(\mathrm{ACA})_{n}-\mathrm{R}_{\mathrm{F}} / \mathrm{h}-\mathrm{BN}$ composites and $\mathrm{R}_{\mathrm{F}}-(\mathrm{DMAA})_{n}-\mathrm{R}_{\mathrm{F}} / \mathrm{h}-\mathrm{BN}$ composites were obtained in $30 \%-79 \%$ and $28 \%-62 \%$ isolated yields, respectively, as the precipitated products after centrifugal separation of the obtained composite methanol solutions. Each composite reaction illustrated in Table 1 can also give the composites products, which were derived from the supernatant methanol solutions, in $6-186 \mathrm{mg}$ and $39-180 \mathrm{mg}$ yields, respectively. The precipitated composite powders after centrifugal separation were shown to exhibit a good dispersibility in not only water but also traditional organic media such as methanol, ethanol, 1,2-dichlorooethane, acetone, dimethyl sulfoxide and $\mathrm{N}, \mathrm{N}$-dimethylformamide. Thus, we have measured the size of these fluorinated h-BN composites in methanol at $25^{\circ} \mathrm{C}$, and the results are also shown in Table 1. Fluorinated composites in Table 1 were nanometer size-controlled very fine nanoparticles from 36 - $129 \mathrm{~nm}$ (Runs 1 - 4) and 17 - 54 $\mathrm{nm}$ (Runs 5 - 8). We have measured the field emission scanning electron micrograph (FE-SEM) of methanol solution of $\mathrm{R}_{\mathrm{F}}-(\mathrm{ACA})_{n}-\mathrm{R}_{\mathrm{F}} / \mathrm{h}-\mathrm{BN}$ nanocomposites before and after calcination at $800^{\circ} \mathrm{C}$, and the results are shown in Figure 1. The FE-SEM picture of the original h-BN particles is also shown in Figure 2, for comparison.

As shown in Figure 1(A), FE-SEM images show that the $\mathrm{R}_{\mathrm{F}}-(\mathrm{ACA})_{n}-\mathrm{R}_{\mathrm{F}} / \mathrm{h}-\mathrm{BN}$ nanocomposites are very fine spherical particles with mean diameter: $60 \mathrm{~nm}$, although we can observe partly agglomeration or aggregation of the pristine h-BN 


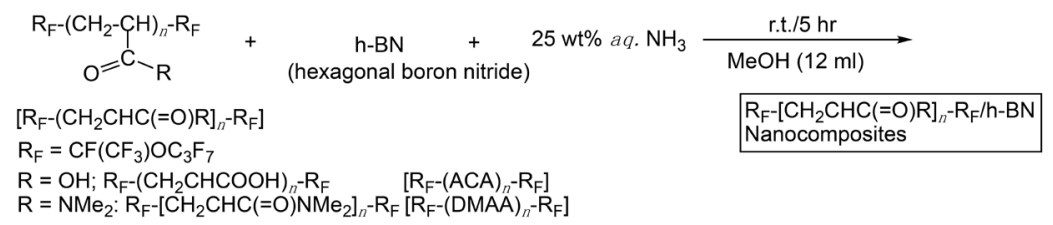

Scheme 1. Preparation of fluoroalkyl end-capped oligomers/h-BN nanocomposites.

Table 1. Preparation of $\mathrm{R}_{\mathrm{F}}-(\mathrm{ACA})_{n}-\mathrm{R}_{\mathrm{F}} / \mathrm{h}-\mathrm{BN}$ nanocomposites and $\mathrm{R}_{\mathrm{F}}-(\mathrm{DMAA})_{n}-\mathrm{R}_{\mathrm{F}} / \mathrm{h}-\mathrm{BN}$ nanocomposites.

\begin{tabular}{|c|c|c|c|c|c|c|}
\hline Run & $\begin{array}{l}\text { Oligomer } \\
(\mathrm{mg})\end{array}$ & $\begin{array}{l}\text { h-BN } \\
(\mathrm{mg})\end{array}$ & $\begin{array}{c}\text { aq. } \mathrm{NH}_{3} \\
(\mathrm{ml})\end{array}$ & $\begin{array}{l}\text { Yield } \\
\text { Product } \\
\text { (mg) }\end{array}$ & $\begin{array}{l}\text { Size of nanoc } \\
\text { Before calcination } \\
(\mathrm{nm}) \pm \text { STD }\end{array}$ & $\begin{array}{l}\text { omposites }^{\text {a) }} \\
\text { After calcination } \\
(\mathrm{nm}) \pm \text { STD }\end{array}$ \\
\hline \multicolumn{7}{|c|}{$\mathrm{R}_{\mathrm{F}}-(\mathrm{ACA})_{n}-\mathrm{R}_{\mathrm{F}}$} \\
\hline 1 & 20 & 100 & 5 & $92(77)^{b)}[11]^{c)}$ & $55.8 \pm 15.2$ & $37.3 \pm 10.3$ \\
\hline 2 & 50 & 100 & 5 & $119(79)^{b)}[6]^{c)}$ & $38.4 \pm 7.6$ & $80.6 \pm 19.3$ \\
\hline 3 & 100 & 100 & 5 & $128(64)^{b)}[14]^{c)}$ & $128.5 \pm 26.6$ & $25.5 \pm 5.3$ \\
\hline 4 & 200 & 100 & 5 & $228(76)^{b)}[18]^{c)}$ & $35.6 \pm 8.2$ & $53.2 \pm 11.8$ \\
\hline 5 & 20 & 100 & 0 & $88(73)^{b)}[24]^{c)}$ & $17.0 \pm 3.5$ & $18.3 \pm 4.7$ \\
\hline 6 & 50 & 100 & 0 & $93(62)^{b)}[50]^{c)}$ & $53.7 \pm 10.0$ & $44.8 \pm 9.1$ \\
\hline 7 & 100 & 100 & 0 & $88(44)^{\mathrm{b})}[76]^{\mathrm{c})}$ & $46.5 \pm 8.9$ & $19.6 \pm 5.0$ \\
\hline 8 & 200 & 100 & 0 & $90(30)^{b)}[186]^{c)}$ & $48.4 \pm 10.0$ & $28.6 \pm 2.9$ \\
\hline \multicolumn{7}{|c|}{$\mathrm{R}_{\mathrm{F}}-(\mathrm{DMAA})_{n}-\mathrm{R}_{\mathrm{F}}$} \\
\hline 9 & 50 & 100 & 5 & $80(53)^{\mathrm{b})}[53]^{\mathrm{c})}$ & $29.4 \pm 8.3$ & $90.1 \pm 13.7$ \\
\hline 10 & 100 & 100 & 5 & $68(34)^{\mathrm{b})}[81]^{\mathrm{c})}$ & $44.0 \pm 5.8$ & $59.6 \pm 9.5$ \\
\hline 11 & 150 & 100 & 5 & $80(32)^{b)}[135]^{c)}$ & $95.2 \pm 24.4$ & $105.5 \pm 19.4$ \\
\hline 12 & 200 & 100 & 5 & $84(28)^{b)}[180]^{c)}$ & $166.7 \pm 37.6$ & $131.7 \pm 25.6$ \\
\hline 13 & 50 & 100 & 0 & $93(62)^{b)}[39]^{c)}$ & $44.1 \pm 9.5$ & $63.4 \pm 10.4$ \\
\hline 14 & 100 & 100 & 0 & $92(46)^{b)}[79]^{c)}$ & $39.0 \pm 10.5$ & $160.9 \pm 30.4$ \\
\hline 15 & 150 & 100 & 0 & $93(37)^{b)}[123]^{c)}$ & $70.8 \pm 13.5$ & $174.2 \pm 40.0$ \\
\hline 16 & 200 & 100 & 0 & $93(31)^{\mathrm{b})}[150]^{\mathrm{c})}$ & $85.2 \pm 17.0$ & $113.2 \pm 25.3$ \\
\hline
\end{tabular}

a) Determined by dynamic light scattering measurements (DLS) in methanol at $25^{\circ} \mathrm{C}$; b) Yield (\%) based on the oligomer and h-BN; c) Isolated product (mg) from the supernatant.

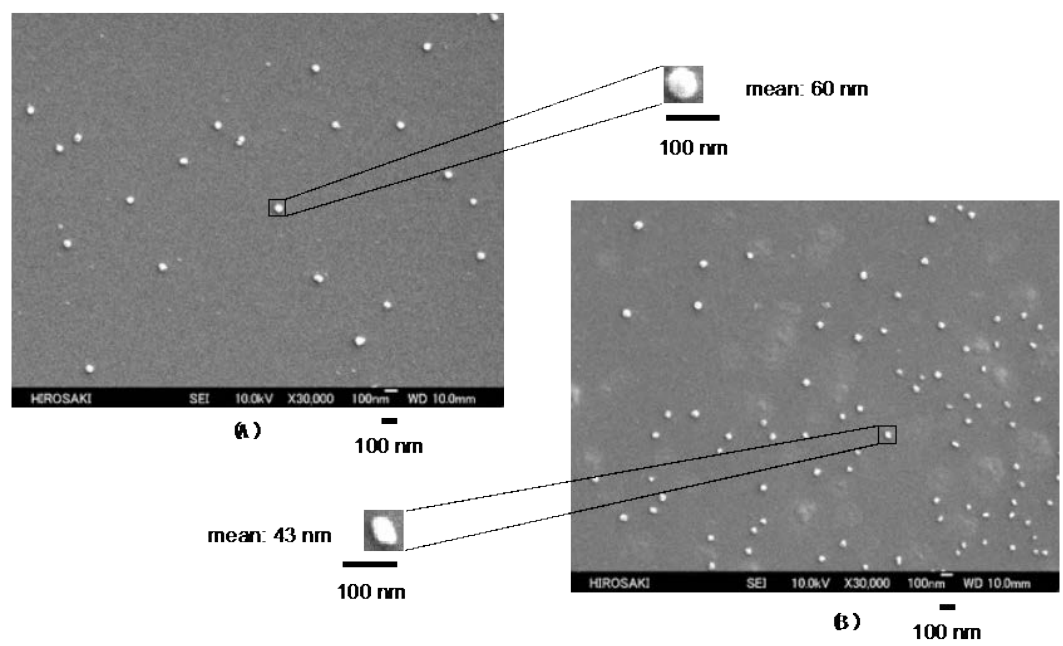

Figure 1. FE-SEM (Field Emission Scanning Electron Microscopy) images of well-dispersed methanol solutions of $\mathrm{R}_{\mathrm{F}}-(\mathrm{ACA})_{n}-\mathrm{R}_{\mathrm{F}} / \mathrm{h}-\mathrm{BN}$ nanocomposites (Run 7 in Table 1) before (A) and after (B) calcination at $800^{\circ} \mathrm{C}$. 


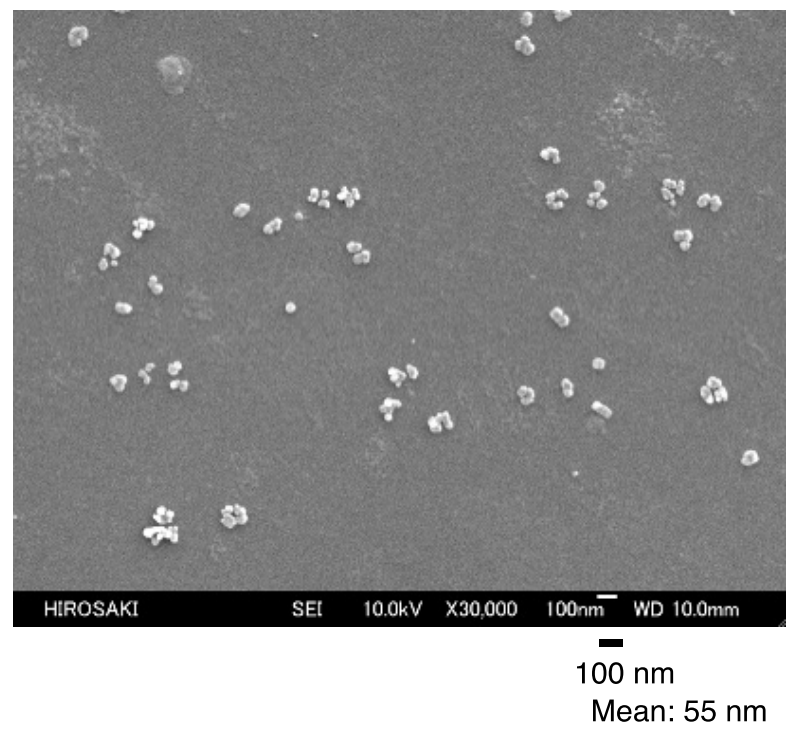

Figure 2. FE-SEM image of the parent h-BN particles in methanol solution.

particles (see Figure 2). Figure $1(\mathrm{~B})$ shows that the $\mathrm{R}_{\mathrm{F}}-(\mathrm{ACA})_{n}-\mathrm{R}_{\mathrm{F}} / \mathrm{h}-\mathrm{BN}$ nanocomposites after calcination at $800^{\circ} \mathrm{C}$ are also similarly fine nanoparticles with mean diameter: $43 \mathrm{~nm}$. In addition, the average particle sizes (60 and $43 \mathrm{~nm}$ ) of the composites before and after calcination determined by FE-SEM measurements were similar to those (47 and $20 \mathrm{~nm}$ ) of the DLS measurements, respectively. FE-SEM measurements also show that $\mathrm{R}_{\mathrm{F}}-(\mathrm{DMAA})_{n}-\mathrm{R}_{\mathrm{F}} / \mathrm{h}-\mathrm{BN}$ nanocomposites before and after calcination at $800^{\circ} \mathrm{C}$ can give very fine spherical nanoparticles with mean diameters: $25 \mathrm{~nm}$ (before calcination) and $55 \mathrm{~nm}$ (after calcination) (see Figure 3). The formation of such very fine nanocomposite particles $(25 \mathrm{~nm})$, compared to that $(55 \mathrm{~nm})$ of the parent $\mathrm{h}$-BN nanoparticles would be due to the higher dispersive ability of the fluoroalkyl end-capped oligomer to produce the primary particles of $\mathrm{h}-\mathrm{BN}$ in the nanocomposites.

We have studied on the XRD spectra of the obtained fluorinated nanocomposites in order to clarify the presence of $\mathrm{h}-\mathrm{BN}$ in the composites. The results are shown in Figure 4 and Figure 5. The XRD spectra of the original $\mathrm{R}_{\mathrm{F}}-(\mathrm{ACA})_{n}-\mathrm{R}_{\mathrm{F}}$ oligomer and $\mathrm{R}_{\mathrm{F}}-(\mathrm{DMAA})_{n}-\mathrm{R}_{\mathrm{F}}$ oligomer are also shown in Figure 6 , for comparison.

As shown in Figure 4 and Figure 5, we were unable to detect the sharp diffraction peaks related to the fluoroalkyl end-capped oligomers in the nanocomposites due to the amorphous characteristics of these oligomers illustrated in Figure 6. However, $\mathrm{R}_{\mathrm{F}}-(\mathrm{ACA})_{n}-\mathrm{R}_{\mathrm{F}} / \mathrm{h}-\mathrm{BN}$ and $\mathrm{R}_{\mathrm{F}}-(\mathrm{DMAA})_{n}-\mathrm{R}_{\mathrm{F}} / \mathrm{h}-\mathrm{BN}$ nanocomposites were found to afford the same diffraction peaks as those of the original $\mathrm{h}-\mathrm{BN}$ nanoparticles, indicating the presence of h-BN in each fluorinated nanocomposite. To verify the presence of the $\mathrm{R}_{\mathrm{F}}-(\mathrm{ACA})_{n}-\mathrm{R}_{\mathrm{F}}$ oligomer in the h-BN nanocomposites, we have studied on the thermal stability of the $\mathrm{R}_{\mathrm{F}}-(\mathrm{ACA})_{n^{-}}$ $\mathrm{R}_{\mathrm{F}} / \mathrm{h}$-BN nanocomposites (Runs 1 - 4) presented in Table 1 by the use of the 
thermogravimetric analyses (TGA), in which the weight loss of the nanocomposites was measured by raising the temperature around $800^{\circ} \mathrm{C}$ (the heating rate: $10^{\circ} \mathrm{C} \mathrm{min}^{-1}$ ) in air atmosphere. Thermal stability of the original h-BN particles and the original $\mathrm{R}_{\mathrm{F}}-(\mathrm{ACA})_{n}-\mathrm{R}_{\mathrm{F}}$ oligomer was also studied, for comparison. The results are shown in Figure 7.

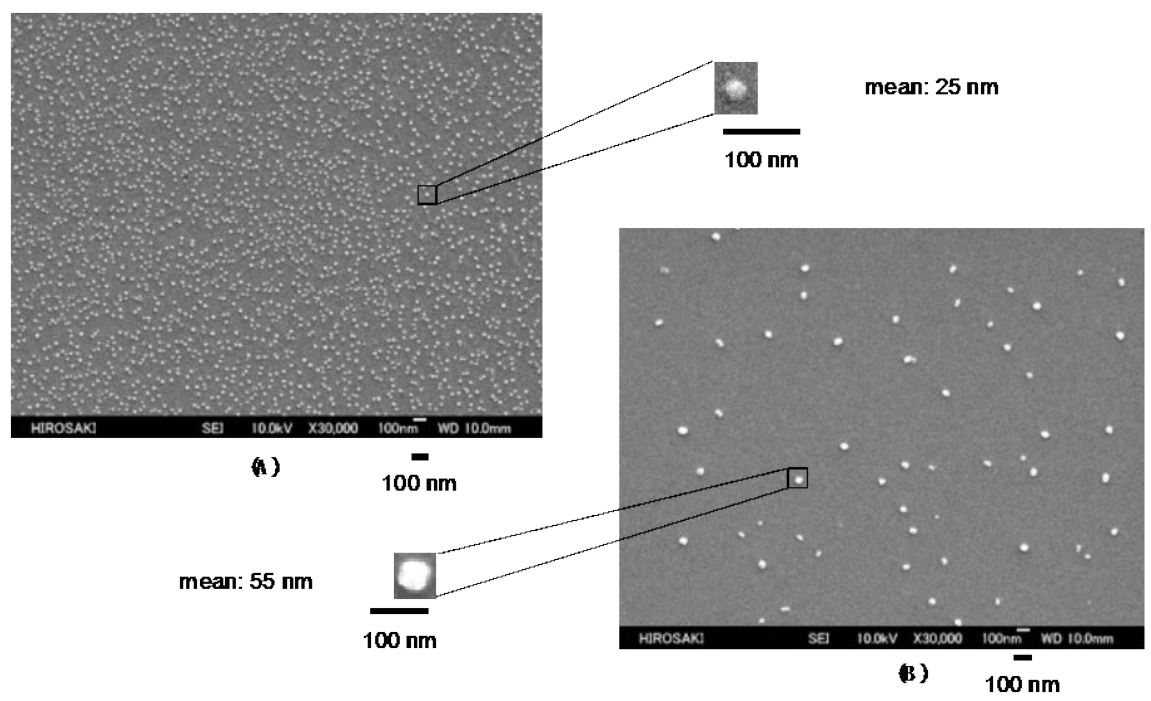

Figure 3. FE-SEM images of well-dispersed methanol solutions of $\mathrm{R}_{\mathrm{F}}-(\mathrm{DMAA})_{n}-\mathrm{R}_{\mathrm{F}} / \mathrm{h}-\mathrm{BN}$ nanocomposites (Run 14 in Table 1) before (A) and after (B) calcination at $800^{\circ} \mathrm{C}$.
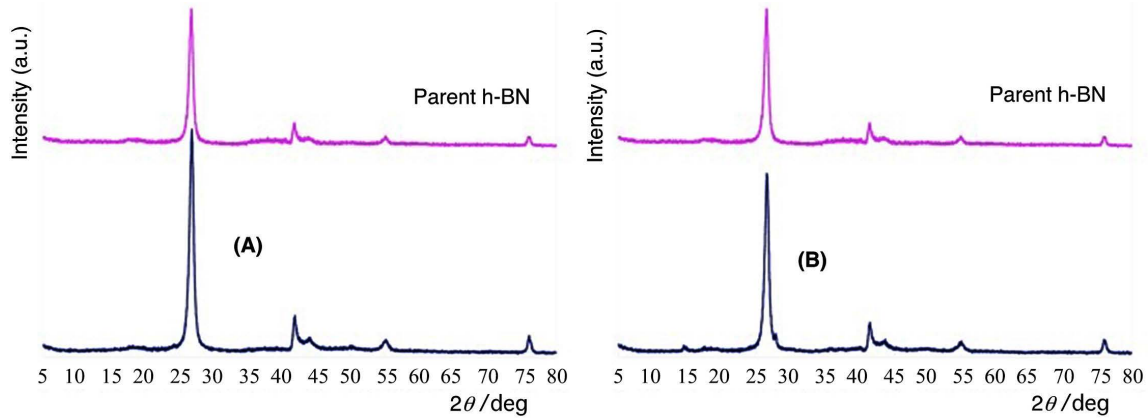

Figure 4. X-ray diffraction patterns of $\mathrm{R}_{\mathrm{F}}-(\mathrm{ACA})_{n}-\mathrm{R}_{\mathrm{F}} / \mathrm{h}-\mathrm{BN}$ nanocomposites (Run 7 in Table 1) before (A) and after (B) calcination at $800^{\circ} \mathrm{C}$.
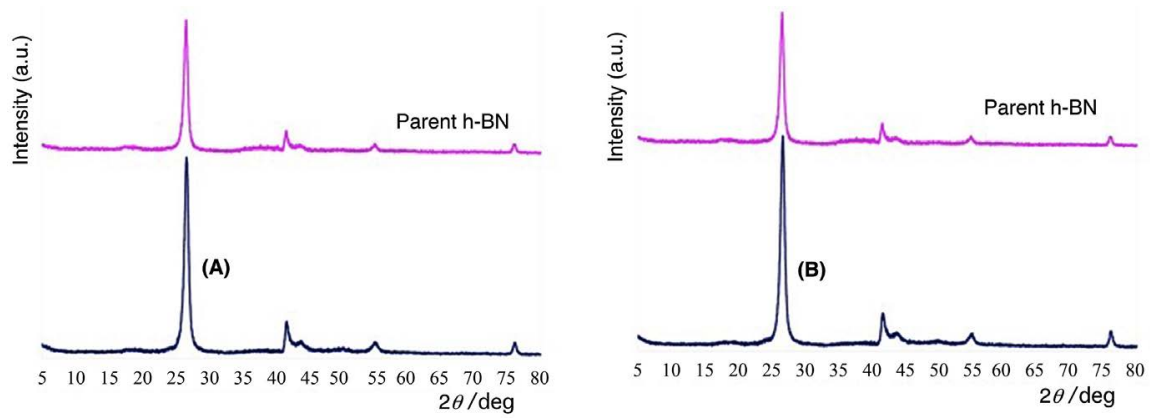

Figure 5. X-ray diffraction patterns of $\mathrm{R}_{\mathrm{F}}-(\mathrm{DMAA})_{n}-\mathrm{R}_{\mathrm{F}} / \mathrm{h}-\mathrm{BN}$ nanocomposites (Run 14 in Table 1) before (A) and after (B) calcination at $800^{\circ} \mathrm{C}$. 


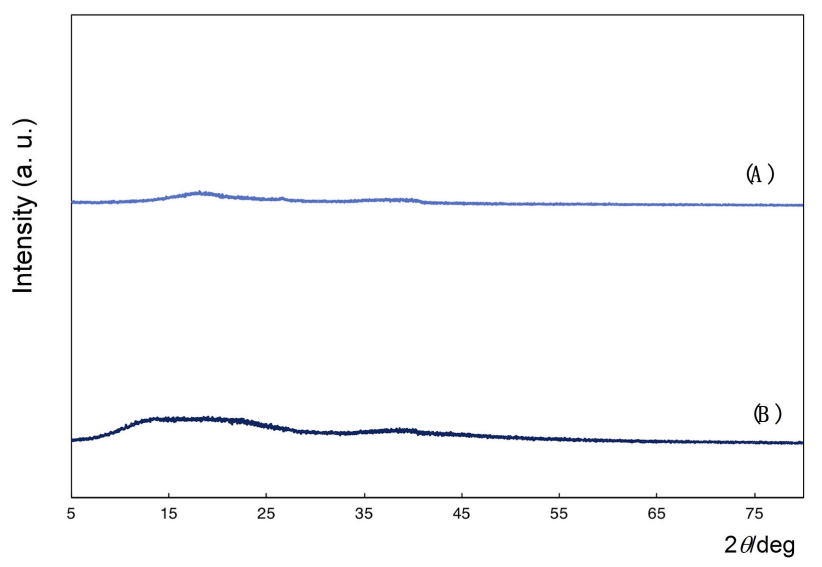

Figure 6. X-ray diffraction patterns of original $\mathrm{R}_{\mathrm{F}}-(\mathrm{ACA})_{n}-\mathrm{R}_{\mathrm{F}}$ oligomer and $\mathrm{R}_{\mathrm{F}}-(\mathrm{DMAA})_{n}-\mathrm{R}_{\mathrm{F}}$ oligomer.

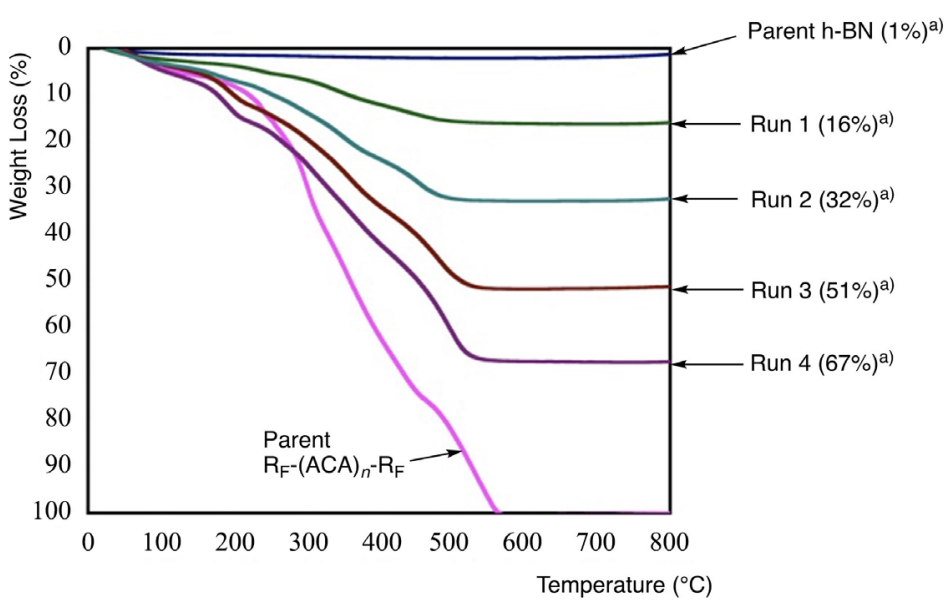

Figure 7. Thermogravimetric analysis of $\mathrm{R}_{\mathrm{F}}-(\mathrm{ACA})_{n}-\mathrm{R}_{\mathrm{F}} / \mathrm{h}-\mathrm{BN}$ nanocomposites, which were prepared under alkaline conditions (Runs $1-4$ in Table 1). a) Weight loss (\%) at $800^{\circ} \mathrm{C}$.

Original h-BN nanoparticles can keep no weigh loss even after calcination at $800^{\circ} \mathrm{C}$, and the pristine $\mathrm{R}_{\mathrm{F}}-(\mathrm{ACA})_{n}-\mathrm{R}_{\mathrm{F}}$ oligomer has a perfect weight loss at around $580^{\circ} \mathrm{C}$ as shown in Figure 7. On the other hand, the $\mathrm{R}_{\mathrm{F}}-(\mathrm{ACA})_{n}-\mathrm{R}_{\mathrm{F}} / \mathrm{h}-\mathrm{BN}$ nanocomposites were found to afford clear weight loss corresponding to the contents of the oligomer in the composites at $800^{\circ} \mathrm{C}$. The weight loss values from $16 \%$ to $67 \%$ at $800^{\circ} \mathrm{C}$ in each nanocomposite are sensitive to the feed ratios of fluorinated oligomer and h-BN employed, increasing with greater feed ratios of the fluorinated oligomer in the fluorinated oligomer/h-BN (see Runs $1-4$ in Table 1). This finding suggests that each $\mathrm{R}_{\mathrm{F}}-(\mathrm{ACA})_{n}-\mathrm{R}_{\mathrm{F}}$ oligomer in the $\mathrm{h}-\mathrm{BN}$ nanocomposites affords a usual flammable characteristic during the calcination process. However, interestingly, $\mathrm{R}_{\mathrm{F}}-(\mathrm{ACA})_{n}-\mathrm{R}_{\mathrm{F}} / \mathrm{h}-\mathrm{BN}$ nanocomposites (Runs 5 8 ), which were prepared under non-catalytic conditions, were unable to afford the weight loss behavior in proportion to the contents of the oligomer in the nanocomposites even after calcination at $800^{\circ} \mathrm{C}$, although the pristine $\mathrm{R}_{\mathrm{F}}$ $(\mathrm{ACA})_{n}-\mathrm{R}_{\mathrm{F}}$ oligomer can give a perfect weight loss at around $580^{\circ} \mathrm{C}$ as shown in 


\section{Figure 8 .}

Thus, we have studied on the TGA measurements of the product derived from the supernatant solution at the purification process for the preparation of $\mathrm{R}_{\mathrm{F}}-(\mathrm{ACA})_{n}-\mathrm{R}_{\mathrm{F}} / \mathrm{h}-\mathrm{BN}$ nanocomposites (Run 7 in Table 1 ) in order to verify the presence of the $\mathrm{R}_{\mathrm{F}}-(\mathrm{ACA})_{n}-\mathrm{R}_{\mathrm{F}}$ oligomer in the $\mathrm{h}-\mathrm{BN}$ nanocomposites as the expected composite reaction product in Scheme 1, and the results are shown in Figure 9.

For the composite reaction illustrated in Table 1 (Run 7), the expected $\mathrm{R}_{\mathrm{F}}-(\mathrm{ACA})_{n}-\mathrm{R}_{\mathrm{F}} / \mathrm{h}-\mathrm{BN}$ nanocomposites were obtained in $88 \mathrm{mg}(44 \%)$ isolated yield as the precipitated product, and the supernatant solution at the purification process for the isolation of this nanocomposite afforded the white powdery product in $76 \mathrm{mg}$ isolated yield. TGA curve related to this product reveals the $92 \%$ weight loss at $800^{\circ} \mathrm{C}$, indicating that the $70 \mathrm{mg}(76 \mathrm{mg} \times 0.92)$ of $\mathrm{R}_{\mathrm{F}}-(\mathrm{ACA})_{n}-\mathrm{R}_{\mathrm{F}}$ oligomer should be present in this product. Thus, the amount of $\mathrm{R}_{\mathrm{F}}-(\mathrm{ACA})_{n}-\mathrm{R}_{\mathrm{F}}$ oligomer in the expected nanocomposites is estimated to be 30 mg [100 mg (feed amount of the oligomer: Run 7 in Table 1) - 70 mg (the oligomer in the supernatant)] to afford the simulated TGA curve, of whose weight loss is $34 \%$ [ $(30 \mathrm{mg} / 88 \mathrm{mg}) \times 100]$ at $800^{\circ} \mathrm{C}$ as shown in Figure 10 .

As indicated above (see Run 7 in Figure 8 and Figure 10), the $R_{F}-(A C A)_{n}-$ $\mathrm{R}_{\mathrm{F}} / \mathrm{h}-\mathrm{BN}$ nanocomposites isolated as the nanocomposite reaction product can give no weight loss behavior corresponding to the content of the oligomer even after calcination at $800^{\circ} \mathrm{C}$. On the other hand, the content of the $\mathrm{R}_{\mathrm{F}}-(\mathrm{ACA})_{n}-\mathrm{R}_{\mathrm{F}}$ oligomer in the h-BN nanocomposites isolated as the composite reaction product was estimated to be $30 \mathrm{mg}$ based on the amount $\left(70 \mathrm{mg}\right.$ ) of the $\mathrm{R}_{\mathrm{F}}$ (ACA $)_{n}-\mathrm{R}_{\mathrm{F}}$ oligomer recovered from the supernatant. Thus, the $\mathrm{R}_{\mathrm{F}}-(\mathrm{ACA})_{n}-\mathrm{R}_{\mathrm{F}}$ oligomer in the $\mathrm{h}-\mathrm{BN}$ nanocomposites should give the weight loss characteristic during the calcination process to provide the simulated TGA curve corresponding to the content (34\%) of the oligomer in the nanocomposites as shown in Figure 10. In addition, the EDX (Energy Dispersive X-ray) spectra measurements of the $\mathrm{R}_{\mathrm{F}}-(\mathrm{ACA})_{n}-\mathrm{R}_{\mathrm{F}} / \mathrm{h}-\mathrm{BN}$ nanocomposites possessing a clear weight loss behavior (Run 3 in Table 1 ) show that the contents of carbon decrease from $24.9 \%$ to $0 \%$ after calcination at $800^{\circ} \mathrm{C}$ to exhibit a flammable characteristic toward the $\mathrm{R}_{\mathrm{F}}-(\mathrm{ACA})_{n}-\mathrm{R}_{\mathrm{F}}$ oligomer in the $\mathrm{h}-\mathrm{BN}$ nanocomposites; however, an effective decrease for the amount (4.2\%) of carbon cannot be observed even after calcination (the content of carbon: $12.9 \%$ ) in the $\mathrm{R}_{\mathrm{F}}-(\mathrm{ACA})_{n}-\mathrm{R}_{\mathrm{F}} / \mathrm{h}-\mathrm{BN}$ nanocomposites possessing no weight loss characteristic (Run 7 in Table 1).

Watanabe et al. previously reported that h-BN can exhibit the fluorescent characteristic through the excitation absorption around $215 \mathrm{~nm}$ [85]. In fact, the simple blend hybrid powders of the $\mathrm{R}_{\mathrm{F}}-(\mathrm{ACA})_{n}-\mathrm{R}_{\mathrm{F}}$ oligomeric white colored powder and h-BN powder can emit fluorescence with a peak maximum at around $370 \mathrm{~nm}$ to create the calibration curve (correlation coefficient: $r=$ $0.9941)$, when the blend hybrids methanol solutions are excited $(\lambda=220 \mathrm{~nm})$ into the intense absorption bands in the UV-vis region as shown in Figure 11. 


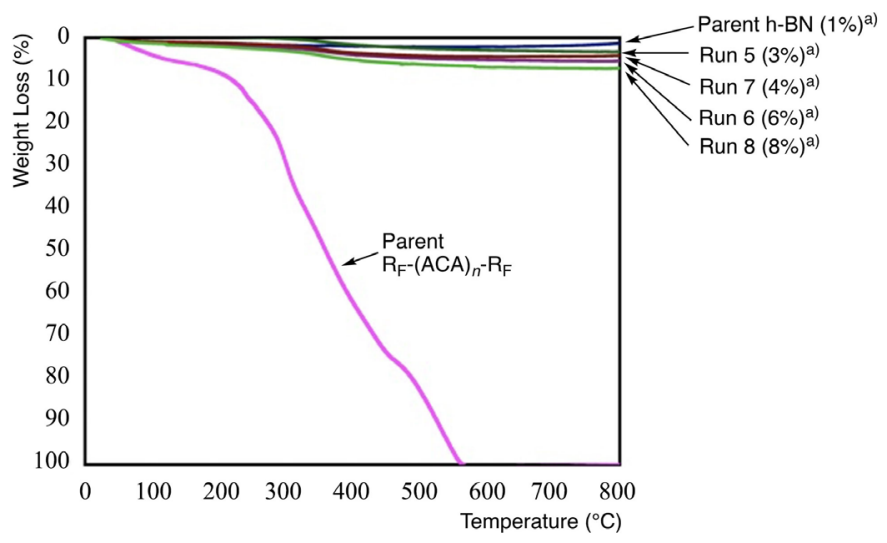

Figure 8. Thermogravimetric analysis of $\mathrm{R}_{\mathrm{F}}-(\mathrm{ACA})_{n}-\mathrm{R}_{\mathrm{F}} / \mathrm{h}-\mathrm{BN}$ nanocomposites, which were prepared under non-catalytic conditions (Runs $5-8$ in Table 1). a) Weight loss (\%) at $800^{\circ} \mathrm{C}$.

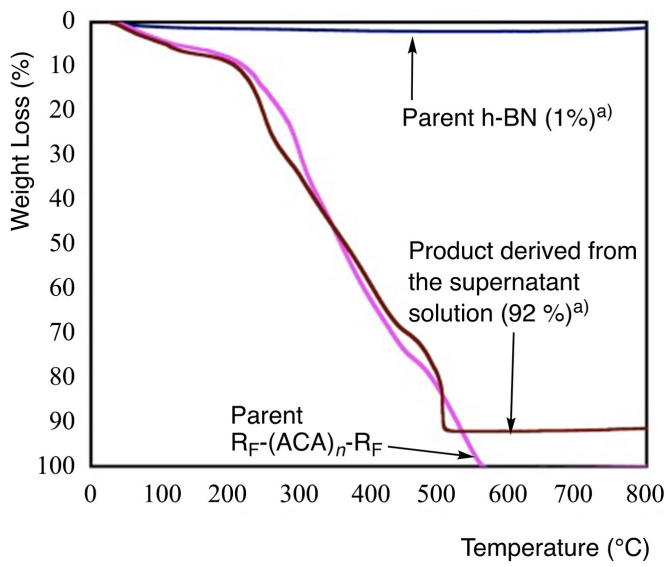

Figure 9. Thermogravimetric analysis of the product derived from the supernatant solution at the purification process for the preparation of the $\mathrm{R}_{\mathrm{F}}-(\mathrm{ACA})_{n}-\mathrm{R}_{\mathrm{F}} / \mathrm{h}-\mathrm{BN}$ nanocomposites (Run 7 in Table 1). a) Weight loss (\%) at $800^{\circ} \mathrm{C}$.

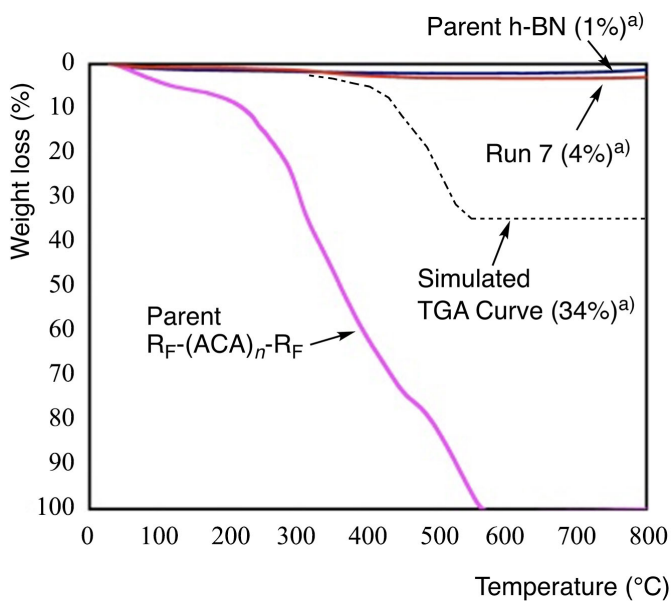

Figure 10. TGA curves of the parent h-BN nanoparticles, the parent $\mathrm{R}_{\mathrm{F}}-(\mathrm{ACA})_{n}-\mathrm{R}_{\mathrm{F}}$ oligomer, the $\mathrm{R}_{\mathrm{F}}-(\mathrm{ACA})_{n}-\mathrm{R}_{\mathrm{F}} / \mathrm{h}-\mathrm{BN}$ nanocomposites (Run 7 in Table 1), and the simulated TGA curve for the $\mathrm{R}_{\mathrm{F}}-(\mathrm{ACA})_{n}-\mathrm{R}_{\mathrm{F}} / \mathrm{h}-\mathrm{BN}$ nanocomposites isolated as the precipitated product. a) Weight loss $(\%)$ at $800^{\circ} \mathrm{C}$. 

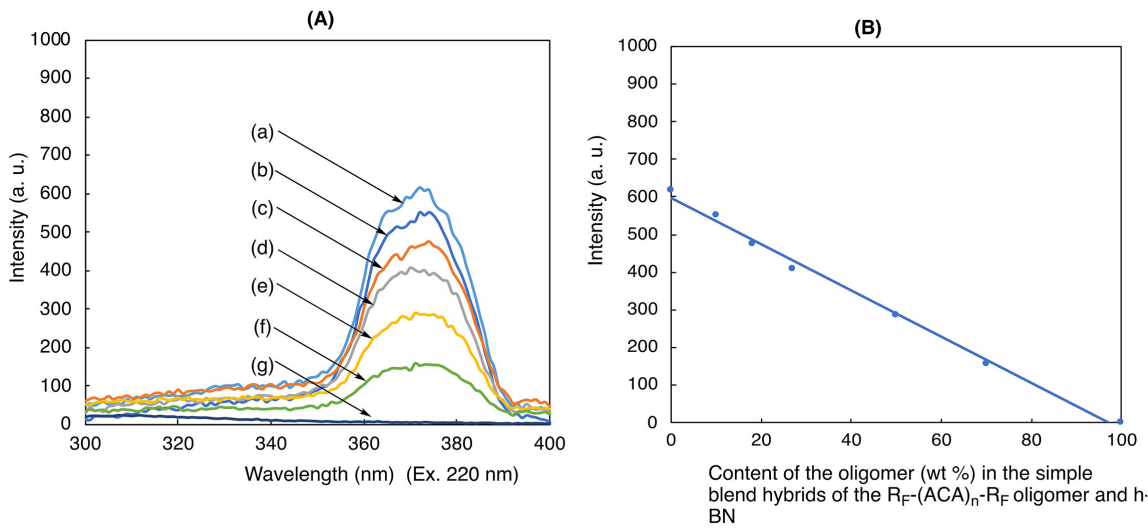

Figure 11. Fluorescent spectra (A) of well-dispersed methanol solutions $\left(0.05 \mathrm{~g} / \mathrm{dm}^{3}\right)$ containing the simple blend hybrids of the $\mathrm{R}_{\mathrm{F}}-(\mathrm{ACA})_{n}-\mathrm{R}_{\mathrm{F}} / \mathrm{h}-\mathrm{BN}$ blend hybrid (Ex. 220 $\mathrm{nm}$ ) and their calibration curve (B) [contents of $\mathrm{R}_{\mathrm{F}}-(\mathrm{ACA})_{n}-\mathrm{R}_{\mathrm{F}}$ oligomer: (a) $0 \mathrm{wt} \%$, (b) $10 \mathrm{wt} \%$, (c) $18 \mathrm{wt} \%$, (d) $27 \mathrm{wt} \%$, (e) $50 \mathrm{wt} \%$, (f) $70 \mathrm{wt} \%$ and (g) $100 \mathrm{wt} \%$ ].

Thus, we tried to measure the fluorescent spectra of the $\mathrm{R}_{\mathrm{F}}-(\mathrm{ACA})_{n}-\mathrm{R}_{\mathrm{F}} / \mathrm{h}-\mathrm{BN}$ nanocomposites (Run 4 in Table 1) before and after calcination at $800^{\circ} \mathrm{C}$, and the results are shown in Figure 12.

As shown in Figure 12, the $\mathrm{R}_{\mathrm{F}}-(\mathrm{ACA})_{n}-\mathrm{R}_{\mathrm{F}}$ /h-BN nanocomposites can afford the fluorescent peak around $370 \mathrm{~nm}$ when the well-dispersed nanocomposite methanol solutions were excited at $220 \mathrm{~nm}$, and its fluorescent intensity shows that the content of the $\mathrm{R}_{\mathrm{F}}-(\mathrm{ACA})_{n}-\mathrm{R}_{\mathrm{F}}$ in the nanocomposites was estimated to be $76 \%$ based on the calibration curve illustrated in Figure 11. On the other hand, the fluorescent intensity of the corresponding nanocomposites after calcination at $800^{\circ} \mathrm{C}$ shows the content of the oligomer was estimated to be $3 \%$ under similar conditions, indicating that this nanocomposite can give a clear weigh loss behavior corresponding to the content of the oligomer during the calcination process. The $\mathrm{R}_{\mathrm{F}}-(\mathrm{ACA})_{n}-\mathrm{R}_{\mathrm{F}} / \mathrm{h}-\mathrm{BN}$ nanocomposites possessing no weigh loss property (Run 8 in Table 1) were found to exhibit the similar fluorescent intensity before and even after calcination at $800^{\circ} \mathrm{C}$ as shown in Figure 13 . The contents of the $\mathrm{R}_{\mathrm{F}}-(\mathrm{ACA})_{n}-\mathrm{R}_{\mathrm{F}}$ oligomer in the nanocomposites before and after calcination were estimated to be $35 \%$ and $39 \%$, respectively, based on the calibration curve in Figure 11. From these findings, it was clarified that our preset $\mathrm{R}_{\mathrm{F}}-(\mathrm{ACA})_{n}-\mathrm{R}_{\mathrm{F}} / \mathrm{h}-\mathrm{BN}$ nanocomposites, which were prepared under alkaline conditions, provide a usual weight loss behavior corresponding to the contents of the oligomer in the composites during the calcination process. In contrast, the $\mathrm{R}_{\mathrm{F}}-(\mathrm{ACA})_{n}-\mathrm{R}_{\mathrm{F}} / \mathrm{h}-\mathrm{BN}$ nanocomposites, which were prepared under non-catalytic conditions, were found to supply no weight loss characteristic even after calcination at $800^{\circ} \mathrm{C}$. In this way, it was clarified that our present $\mathrm{R}_{\mathrm{F}}-(\mathrm{ACA})_{n}-\mathrm{R}_{\mathrm{F}} / \mathrm{h}-\mathrm{BN}$ nanocomposites, which were prepared under non-catalytic conditions, can possess no weight loss ability corresponding to the contents of the oligomer in the composites even after calcination at $800^{\circ} \mathrm{C}$. Next, we tried to study on the thermal stability of the $\mathrm{R}_{\mathrm{F}}-(\mathrm{DMAA})_{n}-\mathrm{R}_{\mathrm{F}} / \mathrm{h}-\mathrm{BN}$ nanocomposites by using the TGA measurements, and the results are shown in Figure 14 and Figure 15. 


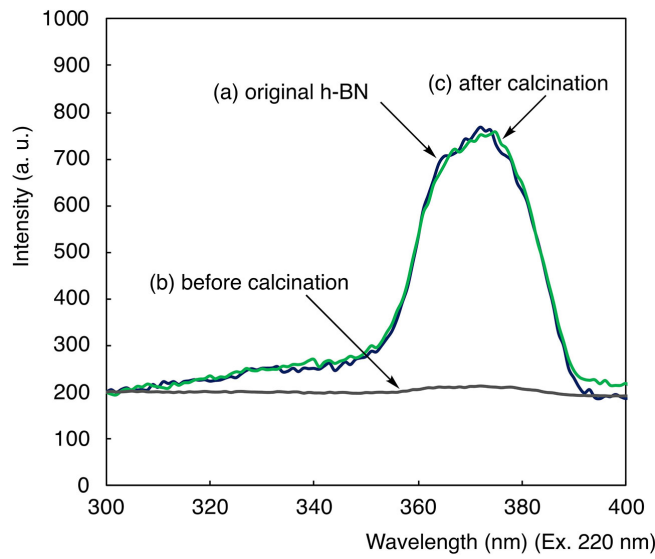

Figure 12. Fluorescent spectra of well-dispersed methanol solutions containing the parent h-BN nanoparticles [(a): $0.05 \mathrm{gdm}^{-3}$ ], the $\mathrm{R}_{\mathrm{F}}-(\mathrm{ACA})_{n}-\mathrm{R}_{\mathrm{F}} / \mathrm{h}-\mathrm{BN}$ nanocomposites before calcination [(b): Run 4 in Table 1, $0.05 \mathrm{gdm}^{-3}$ ], and the $\mathrm{R}_{\mathrm{F}}-(\mathrm{ACA})_{n}-\mathrm{R}_{\mathrm{F}} / \mathrm{h}-\mathrm{BN}$ nanocomposites after calcination at $800^{\circ} \mathrm{C}$ [(c): Run 4 in Table $\left.1,0.05 \mathrm{gdm}^{-3}\right]$.

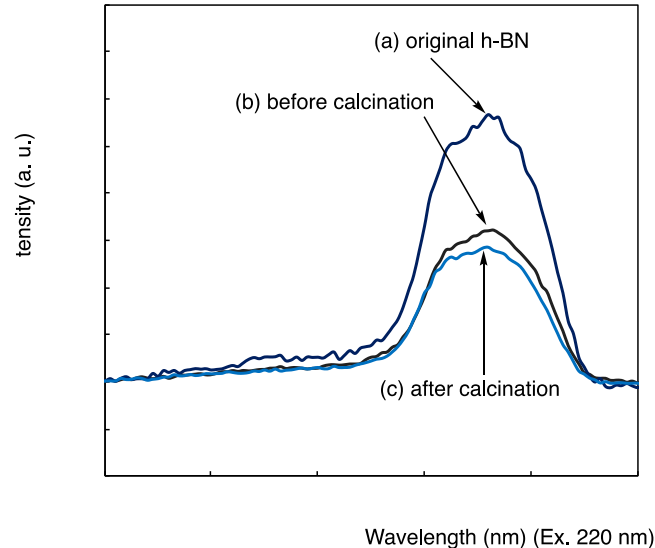

Figure 13. Fluorescent spectra of well-dispersed methanol solutions containing the parent h-BN nanoparticles [(a): $0.05 \mathrm{gdm}^{-3}$ ], the $\mathrm{R}_{\mathrm{F}}-(\mathrm{ACA})_{n}-\mathrm{R}_{\mathrm{F}} / \mathrm{h}-\mathrm{BN}$ nanocomposites before calcination [(b): Run 8 in Table $1 ; 0.05 \mathrm{gdm}^{-3}$ ], and the $\mathrm{R}_{\mathrm{F}}-(\mathrm{ACA})_{n}-\mathrm{R}_{\mathrm{F}} / \mathrm{h}-\mathrm{BN}$ nanocomposites after calcination at $800^{\circ} \mathrm{C}$ [(c): Run 8 in Table $\left.1 ; 0.05 \mathrm{gdm}^{-3}\right]$.

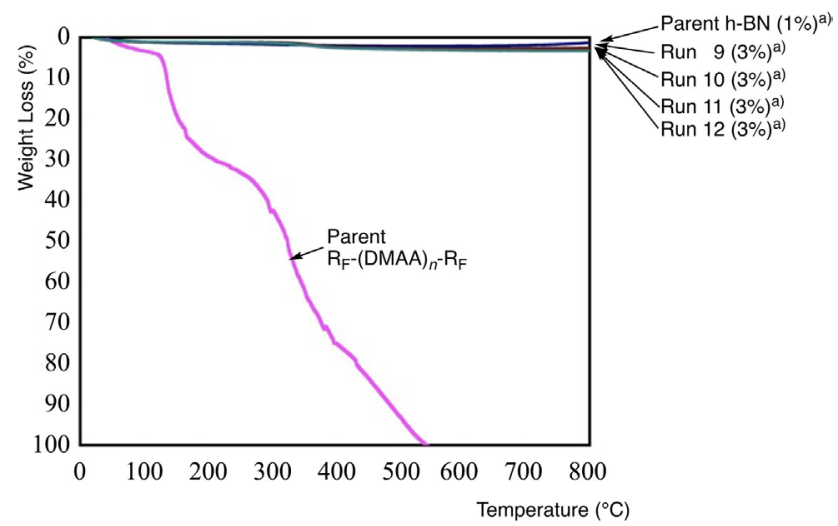

Figure 14. Thermogravimetric analysis of $\mathrm{R}_{\mathrm{F}}-(\mathrm{DMAA})_{n}-\mathrm{R}_{\mathrm{F}} / \mathrm{h}-\mathrm{BN}$ nanocomposites, which were prepared under alkaline conditions (Runs 9 - 12 in Table 1). a) Weight loss (\%) at $800^{\circ} \mathrm{C}$. 


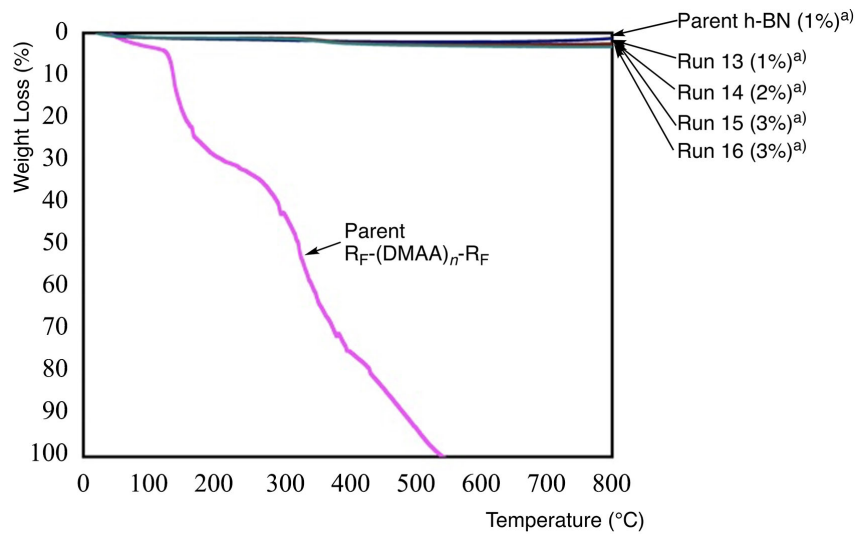

Figure 15. Thermogravimetric analysis of $\mathrm{R}_{\mathrm{F}}-(\mathrm{DMAA})_{n}-\mathrm{R}_{\mathrm{F}} / \mathrm{h}-\mathrm{BN}$ nanocomposites, which were prepared under non-catalytic conditions (Runs 13 - 16 in Table 1). a) Weight loss (\%) at $800^{\circ} \mathrm{C}$.

Unexpectedly, Figure 14 shows that the $\mathrm{R}_{\mathrm{F}}-(\mathrm{DMAA})_{n}-\mathrm{R}_{\mathrm{F}} / \mathrm{h}-\mathrm{BN}$ nanocomposites, which were prepared under alkaline conditions, can give no weight loss behavior even after calcination at $800^{\circ} \mathrm{C}$, although the original $\mathrm{R}_{\mathrm{F}}-(\mathrm{DMAA})_{n}-\mathrm{R}_{\mathrm{F}}$ oligomer can provide a perfect weight loss at around $540^{\circ} \mathrm{C}$, quite different from that of the $\mathrm{R}_{\mathrm{F}}-(\mathrm{ACA})_{n}-\mathrm{R}_{\mathrm{F}} / \mathrm{h}-\mathrm{BN}$ nanocomposites which were prepared under similar conditions illustrated in Figure 7. In addition, the $\mathrm{R}_{\mathrm{F}}-(\mathrm{DMAA})_{n}-\mathrm{R}_{\mathrm{F}} / \mathrm{h}-\mathrm{BN}$ nanocomposites, which were prepared under non-catalytic conditions, enabled each nanocomposite to supply no weight loss behavior even after calcination at $800^{\circ} \mathrm{C}$ (see Figure 15$)$. In order to clarify the presence of the $\mathrm{R}_{\mathrm{F}}-(\mathrm{DMAA})_{n}-\mathrm{R}_{\mathrm{F}}$ oligomer in the h-BN nanocomposites (Runs 10 and 14 in Table 1), the amounts of the $\mathrm{R}_{\mathrm{F}}$-(DMAA) ${ }_{n}-\mathrm{R}_{\mathrm{F}}$ oligomer in the supernatants have been estimated to be $81 \mathrm{mg}$ and $79 \mathrm{mg}$, respectively, by the use of the TGA measurements of the supernatants. Thus, each obtained nanocomposite should afford the simulated TGA curves, of whose weight loss at $800^{\circ} \mathrm{C}$ are $28 \%$ [19 mg (100 mg (feed amount of oligomer) $-81 \mathrm{mg}) / 68 \mathrm{mg}$ (precipitated nanocomposite yield) $\times 100$ ] and $23 \%$ [21 $\mathrm{mg}(100 \mathrm{mg}-79 \mathrm{mg}) / 92 \mathrm{mg}]$, respectively. However, the TGA curves related to the $\mathrm{R}_{\mathrm{F}}-(\mathrm{DMAA})_{n}-\mathrm{R}_{\mathrm{F}} / \mathrm{h}-\mathrm{BN}$ nanocomposites (Runs 10 and 14) reveal no weight loss in each case (see Figure 10 and Figure 11), indicating that the $\mathrm{R}_{\mathrm{F}}-(\mathrm{DMAA})_{n}-\mathrm{R}_{\mathrm{F}}$ oligomer can exhibit no weight loss behavior in the h-BN nanocomposites even after calcination at $800^{\circ} \mathrm{C}$. XRD spectra for the $\mathrm{R}_{\mathrm{F}}$ (DMAA) ${ }_{n}-\mathrm{R}_{\mathrm{F}} / \mathrm{h}-\mathrm{BN}$ nanocomposites (Runs 10 and 14) were found to afford the same XRD diffraction patterns to that of the original h-BN nanoparticle, respectively (data not shown), suggesting the presence of the h-BN in the composites before and after calcination.

We previously reported that the surface arrangement of fluoroalkylsegments on the modified PMMA [poly(methyl methacrylate)] surface owing to the creation of the oleophobic property imparted by fluorine can be achieved by using fluoroalkyl end-capped cooligomers [86]. In fact, fluoroalkyl end-capped cooligomeric nanocomposite-encapsulated fullerenes were applied to the surface modification of PMMA to exhibit a good oleophobicity imparted by fluorine on 
the modified film surfaces [73]. Thus, we tried to prepare the modified PMMA films treated with the $\mathrm{R}_{\mathrm{F}}-(\mathrm{ACA})_{n}-\mathrm{R}_{\mathrm{F}} / \mathrm{h}-\mathrm{BN}$ nanocomposites (Runs 3 and 7 in Table 1) and the $\mathrm{R}_{\mathrm{F}}-(\mathrm{DMAA})_{n}-\mathrm{R}_{\mathrm{F}} / \mathrm{h}-\mathrm{BN}$ nanocomposites (Runs 10 and 14 in Table 1) by casting method, and the results are depicted in Table 2.

Table 2 shows that each modified PMMA surface treated with the $\mathrm{R}_{\mathrm{F}}-(\mathrm{ACA})_{n^{-}}$ $\mathrm{R}_{\mathrm{F}} / \mathrm{h}-\mathrm{BN}$ nanocomposites (Runs 3 and 7 ) and the $\mathrm{R}_{\mathrm{F}}-(\mathrm{DMAA})_{n}-\mathrm{R}_{\mathrm{F}} / \mathrm{h}-\mathrm{BN}$ nanocomposites (Runs 10 and 14) can give an oleophobic property imparted by fluoroalkyl segments in the nanocomposites, because the dodecane contact angle values are 13 - 14 degrees. In contrast, the reverse side affords not oleophobic but oleophilic characteristic (dodecane contact angle value: 0 degree) in each case, quite similar to that of the modified PMMA film treated with the pristine

Table 2. Contact angles of dodecane on the modified PMMA film surface treated with the $\mathrm{R}_{\mathrm{F}}-(\mathrm{ACA})_{n}-\mathrm{R}_{\mathrm{F}} / \mathrm{h}-\mathrm{BN}$ nanocomposites (Runs 3 and 7 in Table 1 ) and the $\mathrm{R}_{\mathrm{F}}-(\mathrm{DMAA})_{n}{ }^{-}$ $\mathrm{R}_{\mathrm{F}} / \mathrm{h}-\mathrm{BN}$ nanocomposites (Runs 10 and 14 in Table 1 ) before and after calcination at $800^{\circ} \mathrm{C}^{*}$

\begin{tabular}{|c|c|c|c|}
\hline \multicolumn{4}{|c|}{ Contact angle (Degree) } \\
\hline \multicolumn{3}{|c|}{ Run } & Dodecane \\
\hline \multirow[t]{5}{*}{3} & \multicolumn{3}{|c|}{$\left[\mathrm{R}_{\mathrm{F}}-(\mathrm{ACA})_{n}-\mathrm{R}_{\mathrm{F}} / \mathrm{h}-\mathrm{BN}\right.$ nanocomposites $]$} \\
\hline & \multirow[t]{2}{*}{ Before calcination } & Surface side & 14 \\
\hline & & Reverse side & 0 \\
\hline & \multirow[t]{2}{*}{ After calcination } & Surface side & 0 \\
\hline & & Reverse side & 0 \\
\hline \multirow[t]{5}{*}{7} & \multicolumn{3}{|c|}{$\left[\mathrm{R}_{\mathrm{F}}-(\mathrm{ACA})_{n}-\mathrm{R}_{\mathrm{F}} / \mathrm{h}-\mathrm{BN}\right.$ nanocomposites $]$} \\
\hline & \multirow[t]{2}{*}{ Before calcination } & Surface side & 14 \\
\hline & & Reverse side & 0 \\
\hline & \multirow[t]{2}{*}{ After calcination } & Surface side & 10 \\
\hline & & Reverse side & 0 \\
\hline \multirow[t]{5}{*}{10} & \multicolumn{3}{|c|}{$\left[\mathrm{R}_{\mathrm{F}}-(\mathrm{DMAA})_{n}-\mathrm{R}_{\mathrm{F}} / \mathrm{h}-\mathrm{BN}\right.$ nanocomposites $]$} \\
\hline & \multirow[t]{2}{*}{ Before calcination } & Surface side & 13 \\
\hline & & Reverse side & 0 \\
\hline & \multirow[t]{2}{*}{ After calcination } & Surface side & 14 \\
\hline & & Reverse side & 0 \\
\hline \multirow[t]{9}{*}{14} & \multicolumn{3}{|c|}{$\left[\mathrm{R}_{\mathrm{F}}-(\mathrm{DMAA})_{n}-\mathrm{R}_{\mathrm{F}} / \mathrm{h}-\mathrm{BN}\right.$ nanocomposites] } \\
\hline & \multirow[t]{2}{*}{ Before calcination } & Surface side & 13 \\
\hline & & Reverse side & 0 \\
\hline & \multirow[t]{2}{*}{ After calcination } & Surface side & 16 \\
\hline & & Reverse side & 0 \\
\hline & \multirow[t]{2}{*}{$\mathrm{h}-\mathrm{BN}^{* *}$} & Surface side & 0 \\
\hline & & Reverse side & 0 \\
\hline & \multirow[t]{2}{*}{ Parent PMMA film } & Surface side & 0 \\
\hline & & Reverse side & 0 \\
\hline
\end{tabular}

${ }^{*}$ The content of each nanocomposite based on PMMA is $1 \mathrm{wt} \% .{ }^{*}$ Used pristine $\mathrm{h}-\mathrm{BN}$ nanoparticles and PMMA for the preparation of modified PMMA film are $10 \mathrm{mg}$ and $990 \mathrm{mg}$, respectively. 
h-BN nanoparticles or the original PMMA film (the surface and reverse side are 0 degree, respectively). These findings suggest that the $\mathrm{R}_{\mathrm{F}}-(\mathrm{ACA})_{n}-\mathrm{R}_{\mathrm{F}} / \mathrm{h}-\mathrm{BN}$ nanocomposites and the $\mathrm{R}_{\mathrm{F}}-(\mathrm{DMAA})_{n}-\mathrm{R}_{\mathrm{F}} / \mathrm{h}-\mathrm{BN}$ nanocomposites before calcination should be arranged regularly on the modified PMMA surface to exhibit the oleophobic characteristic imparted by fluoroalkyl segments in the nanocomposites. On the other hand, the $\mathrm{R}_{\mathrm{F}}-(\mathrm{ACA})_{n}-\mathrm{R}_{\mathrm{F}} / \mathrm{h}-\mathrm{BN}$ nanocomposites (Run 3 ) after calcination were found to give not oleophobic but oleophilic characteristic on the modified surface, as well as that of the original PMMA film surface or the modified PMMA film treated with the h-BN nanoparticles, indicating that this nanocomposite can give the usual weight loss behavior during the calcination process. However, interestingly, it was demonstrated that the $\mathrm{R}_{\mathrm{F}}-(\mathrm{ACA})_{n}-\mathrm{R}_{\mathrm{F}} / \mathrm{h}-\mathrm{BN}$ nanocomposites (Run 7 in Table 2) and $\mathrm{R}_{\mathrm{F}}$ (DMAA) $-\mathrm{R}_{\mathrm{F}} / \mathrm{h}-\mathrm{BN}$ nanocomposites (Runs 10 and 14 in Table 2) after calcination can afford a good oleophobic property on the modified PMMA surface, because dodecane contact angle values are 10 - 16 degrees as shown in Table 2.

It was previously reported that the similar fluoroalkyl end-capped acrylamidetype cooligomer possessing an antibacterial activity (see Chart 1) is applicable to

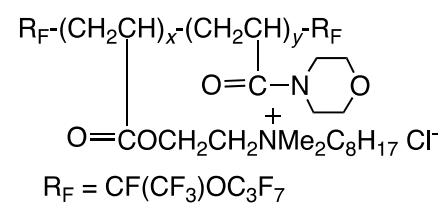

Chart 1

the surfacemodification of PMMA to exhibit not only the surface antibacterial activity but also the oleophobic characteristic related to the fluoroalkyl segments in the cooligomer on the modified PMMA surface [86]. In this case, the dodecane contact angle value on the modified PMMA film surface treated with this cooligomer (the content of cooligomer based on PMMA is the same to that (1 wt\%) of the modified PMMA films treated with the nanocomposites illustrated in Table 2) is 10 degrees, although the dodecane contact angle value of the parent PMMA film surface is 0 degree [86]. From this finding, the dodecane contact angle values from 10 to 16 degrees on the modified PMMA film surfaces treated with the present fluorinated oligomers/h-BN nanocomposites after calcination (Runs 7, 10 and 14 in Table 2) suggest strongly that the present fluorinated oligomers in the nanocomposites possessing no weight loss behavior should be arranged regularly on the modified PMMA film surface to exhibit an oleophobic characteristic on the surface. These findings suggest that such fluorinated h-BN nanocomposites should give no weight loss characteristic in the h-BN nanocomposites even after calcination to afford the oleophobic property imparted by fluoroalkyl segments in the oligomer on the modified PMMA surface. Especially, EDX spectra measurements of the $\mathrm{R}_{\mathrm{F}}-(\mathrm{DMAA})_{n}-\mathrm{R}_{\mathrm{F}} / \mathrm{h}-\mathrm{BN}$ nanocomposites (Run 14 in Table 1) also show the similar amounts of carbons before (6.5\%) and after (16.5\%) calcination of the nanocomposites as well as the $\mathrm{R}_{\mathrm{F}}-(\mathrm{ACA})_{n}-\mathrm{R}_{\mathrm{F}} / \mathrm{h}-\mathrm{BN}$ 
nanocomposites [Run 7 in Table 1: amounts of carbons: before (4.2\%) and after $(12.9 \%)$ calcination], indicating that these fluorinated oligomers should provide no weight loss behavior even after calcination in the nanocomposite cores.

In this way, it was clarified that $\mathrm{R}_{\mathrm{F}}-(\mathrm{ACA})_{n}-\mathrm{R}_{\mathrm{F}} / \mathrm{h}-\mathrm{BN}$ nanocomposites, which were prepared under alkaline conditions, can give a clear weight loss behavior corresponding to the contents of the oligomer during the calcination process. In contrast, $\mathrm{R}_{\mathrm{F}}-(\mathrm{ACA})_{n}-\mathrm{R}_{\mathrm{F}} / \mathrm{h}-\mathrm{BN}$ nanocomposites, which were prepared under non-catalytic conditions, were found to afford no weight loss behavior even after calcination at $800^{\circ} \mathrm{C}$. The edge planes of h-BN have functional groups such as hydroxy and amino groups. [4] [5] The hydroxy groups in h-BN can react with carboxylic acids $[\mathrm{RC}(=\mathrm{O}) \mathrm{OH}]$ and trialkoxysilanes $\left[(\mathrm{RO})_{3} \mathrm{Si}-\mathrm{R}^{\prime}\right]$ to afford the corresponding functionalized h-BN derivatives [48] [87]. Thus, our present $\mathrm{R}_{\mathrm{F}}-(\mathrm{ACA})_{n}-\mathrm{R}_{\mathrm{F}} / \mathrm{h}-\mathrm{BN}$ nanocomposites, which were prepared under non-catalytic conditions, can interact with the hydroxy and amino groups in h-BN to afford the corresponding fluorinated $\mathrm{h}-\mathrm{BN}$ nanocomposite derivatives. Such strong interaction between the carboxy segments in the $\mathrm{R}_{\mathrm{F}}-(\mathrm{ACA})_{n}-\mathrm{R}_{\mathrm{F}}$ oligomer and the hydroxy or amino groups in the $\mathrm{h}-\mathrm{BN}$ should enable the $\mathrm{R}_{\mathrm{F}}-(\mathrm{ACA})_{n}-\mathrm{R}_{\mathrm{F}}$ oligomer in the nanocomposites to afford no weight loss behavior even after calcination (see Scheme 2). In contrast, $\mathrm{R}_{\mathrm{F}}-(\mathrm{ACA})_{n}-\mathrm{R}_{\mathrm{F}} / \mathrm{h}-\mathrm{BN}$ nanocomposites, which were prepared under alkaline conditions, afforded a clear weight loss corresponding to the contents of the oligomer in the nanocomposites, suggesting that the carboxy groups in the oligomer would interact preferentially with ammonia during the preparative process in Scheme 1 to produce the carboxylate anion units $\left(-\mathrm{COO}^{-}\right)$. Such units could not interact with the hydroxy groups or amino groups in the h-BN to provide no weight loss behavior.

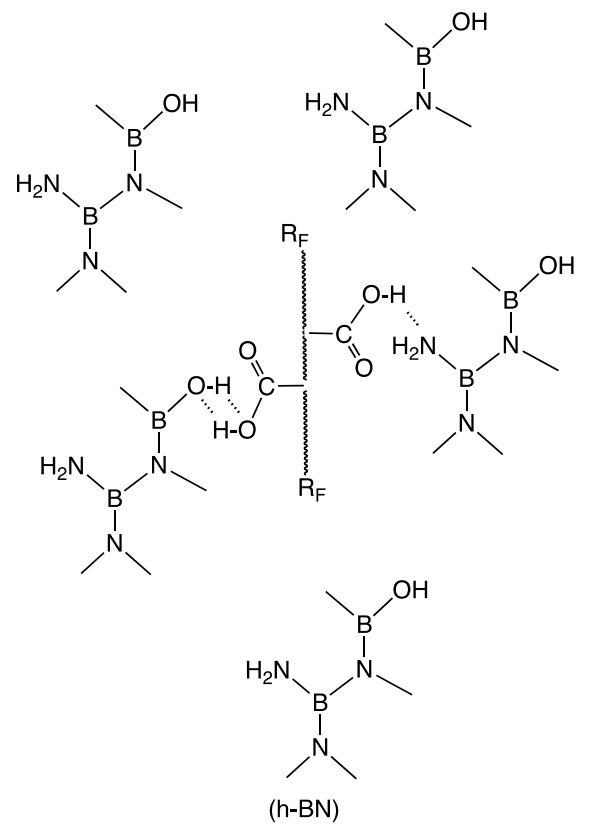

Scheme 2. Schematic illustration for the interaction of $\mathrm{h}-\mathrm{BN}$ and $\mathrm{R}_{\mathrm{F}}-(\mathrm{ACA})_{n}-\mathrm{R}_{\mathrm{F}}$ oligomer. 
On the other hand, the $\mathrm{R}_{\mathrm{F}}-(\mathrm{DMAA})_{n}-\mathrm{R}_{\mathrm{F}} / \mathrm{h}-\mathrm{BN}$ nanocomposites, which were prepared under non-catalytic and alkaline conditions, can give no weight loss behavior corresponding to the contents of the oligomer in the composites even after calcination at $800^{\circ} \mathrm{C}$. Huang et al. reported that boron nitride nanotubes [BNNTs: $>\mathrm{B}-\mathrm{N}<$ ], of whose $\mathrm{B}-\mathrm{N}$ bonding consists of the $2 \mathrm{p} \pi-2 \mathrm{p} \pi$ overlapping, can interact with dimethyl sulfoxide [DMSO: ${ }^{(\delta-)} \mathrm{O}=\mathrm{S}^{(\delta+)} \mathrm{Me}_{2}$ ] through the nucleophilic attack from $\mathrm{O}$ to $\mathrm{B}$ and the electrophilic attack from $\mathrm{S}$ to $\mathrm{N}$ to weaken the B-N bond, affording the cleaved BNNTs derivatives [11]. Therefore, since our present fluoroalkyl end-capped DMAA oligomer possesses the amide units $[-\mathrm{C}(=\mathrm{O}) \mathrm{N}<]$ in the oligomer side chain, this amide unit in oligomer would interact effectively with the $>\mathrm{B}-\mathrm{N}<$ bond to afford the $\mathrm{R}_{\mathrm{F}}-(\mathrm{DMAA})_{n}-\mathrm{R}_{\mathrm{F}} / \mathrm{h}-\mathrm{BN}$ nanocomposites as shown in the following Schematic interaction. Such interaction would provide no weight loss behavior toward the $\mathrm{R}_{\mathrm{F}}-(\mathrm{DMAA})_{n}-\mathrm{R}_{\mathrm{F}}$ oligomer in the h-BN nanocomposites even after calcination.

We previously reported that fluoroalkyl end-capped $N$-(1,1-dimethyl3-oxobutyl)acrylamide oligomer $\left[\mathrm{R}_{\mathrm{F}}-(\mathrm{DOBAA})_{n}-\mathrm{R}_{\mathrm{F}}\right] / \mathrm{SiO}_{2}$ nanocomposites, which were prepared by the sol-gel reaction of tetraethoxysilane in the presence of the corresponding oligomer and the silica nanoparticles under alkaline conditions, exhibit no weight loss characteristic even after calcination at $800^{\circ} \mathrm{C}$ [60] [64] [77] [88] [89]. It was suggested that ammonium hexafluorosilicate should be formed through the dehydrofluorination between the amide protons and fluorines in oligomer during the nanocomposite reactions, and the effective interaction between ammonium hexafluorosilicate and $\mathrm{R}_{\mathrm{F}}-(\mathrm{DOBBA})_{n}-\mathrm{R}_{\mathrm{F}}$ oligomer in silica gel matrices should afford a nonflammable characteristic for this fluorinated oligomer [88] [89] [90]. Especially, the formation of ammonium hexafluorosilicate during this nanocomposite reaction under alkaline conditions can be attributed to the very strong $(129 \mathrm{kcal} / \mathrm{mol}) \mathrm{Si}-\mathrm{F}$ bond [91]. In contrast, $\mathrm{R}_{\mathrm{F}}$ (DMAA) ${ }_{n}-\mathrm{R}_{\mathrm{F}} / \mathrm{SiO}_{2}$ nanocomposites can decompose completely at $800^{\circ} \mathrm{C}$ to afford the weight loss in proportion to the contents of $\mathrm{R}_{\mathrm{F}}-(\mathrm{DMAA})_{n}-\mathrm{R}_{\mathrm{F}}$ oligomer in composites, due to the absence of the amide protons in oligomer to produce the ammonium hexafluorosilicate [60] [90]. No formation of ammonium hexafluorosilicate enables the $\mathrm{R}_{\mathrm{F}}-(\mathrm{ACA})_{n}-\mathrm{R}_{\mathrm{F}} / \mathrm{SiO}_{2}$ nanocomposites to afford the perfect weight loss corresponding to the contents of oligomer in the composites after calcination [60] [90]. Therefore, the synergistic interactions derived from not only the interactions between the amide units in the oligomer and h-BN depicted in Scheme 3 but also noncovalent B ... F interactions between the h-BN and fluorines in oligomers would afford a perfect no weight loss characteristic toward the pristine $\mathrm{R}_{\mathrm{F}}-(\mathrm{DMAA})_{n}-\mathrm{R}_{\mathrm{F}}$ oligomer even after calcination at $800^{\circ} \mathrm{C}$, due to the stronger B-F bond $(183 \mathrm{kcal} / \mathrm{mol})$ [92] than that $(129 \mathrm{kcal} / \mathrm{mol})$ of the Si-F bond [91]. Similarly, the synergistic interaction derived from not only the interaction between the hydroxy or amino groups in the h-BN and the carboxy groups in the $\mathrm{R}_{\mathrm{F}}-(\mathrm{ACA})_{n}-\mathrm{R}_{\mathrm{F}}$ oligomer illustrated in Scheme 2 , but also noncovalent $\mathrm{B}$... F interactions between the h-BN and fluorines in oligomer would 


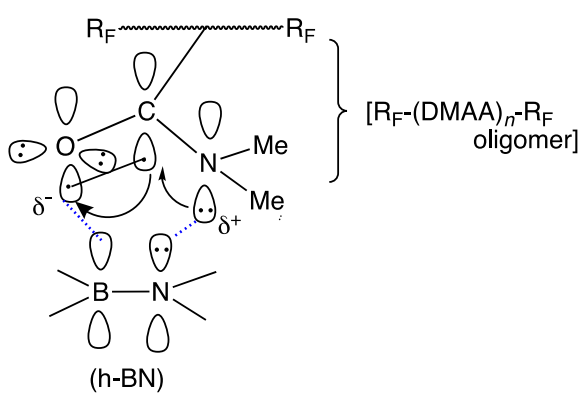

Scheme 3. Schematic illustration for the interaction of h-BN with $\mathrm{R}_{\mathrm{F}}-(\mathrm{DMAA})_{n}-\mathrm{R}_{\mathrm{F}}$ oligomer.

afford no weight loss even after calcination toward the $\mathrm{R}_{\mathrm{F}}-(\mathrm{ACA})_{n}-\mathrm{R}_{\mathrm{F}} / \mathrm{h}-\mathrm{BN}$ nanocomposites, which were prepared under non-catalytic conditions.

\section{Conclusion}

Fluoroalkyl end-capped acrylic acid oligomer/h-BN nanocomposites $\left[\mathrm{R}_{\mathrm{F}}\right.$ $\left.(\mathrm{ACA})_{n}-\mathrm{R}_{\mathrm{F}} / \mathrm{h}-\mathrm{BN}\right]$, which were prepared under alkaline conditions, were found to give a clear weight loss behavior corresponding to the contents of oligomer after calcination at $800^{\circ} \mathrm{C}$; however, $\mathrm{R}_{\mathrm{F}}-(\mathrm{ACA})_{n}-\mathrm{R}_{\mathrm{F}} / \mathrm{h}-\mathrm{BN}$ nanocomposites obtained from the non-catalytic conditions could give no weight loss behavior even after calcination at $800^{\circ} \mathrm{C}$. On the other hand, fluoroalkyl end-capped $N, N$-dimethylacrylamide oligomer/h-BN nanocomposites $\left[\mathrm{R}_{\mathrm{F}}-(\mathrm{DMAA})_{n}-\mathrm{R}_{\mathrm{F}} / \mathrm{h}-\mathrm{BN}\right]$, which were prepared under alkaline or non-catalytic conditions, afforded no weight loss characteristic even after calcination at $800^{\circ} \mathrm{C}$, giving the quite similar TGA curve to that of the original h-BN nanoparticles. The $\mathrm{R}_{\mathrm{F}}-(\mathrm{ACA})_{n}-\mathrm{R}_{\mathrm{F}} / \mathrm{h}-\mathrm{BN}$ nanocomposites possessing a clear weight loss behavior were applied to the surface modification of PMMA film to exhibit the oleophobic property related to the fluoroalkyl groups on the modified surface. However, the corresponding nanocomposites after calcination at $800^{\circ} \mathrm{C}$ afforded an oleophilic property on the modified PMMA surface, quite similar to that of the original PMMA film surface, indicating that $\mathrm{R}_{\mathrm{F}}-(\mathrm{ACA})_{n}-\mathrm{R}_{\mathrm{F}}$ oligomer could give a flammable characteristic during the calcination process. The modified PMMA film surfaces treated with the $\mathrm{R}_{\mathrm{F}}$-(DMAA) $)_{n}-\mathrm{R}_{\mathrm{F}} / \mathrm{h}-\mathrm{BN}$ nanocomposites obtained under alkaline or non-catalytic conditions can supply an oleophobic property related to the fluoroalkyl groups in the nanocomposites on the surfaces. More interestingly, the corresponding nanocomposites after calcination at $800^{\circ} \mathrm{C}$ can also provide a good oleophobic property on the modified PMMA surfaces. In this way, our present fluorinated oligomer/h-BN nanocomposites possessing no weight loss behavior have high potential for the development of nonflammable fluorinated functional oligomeric materials into a wide variety of fields.

\section{Funding}

This work was partially supported by a Grant-in-Aid for Scientific Research 16K05891 from the Ministry of Education, Science, Sports, and Culture, Japan. 


\section{Conflicts of Interest}

The authors declare no conflicts of interest regarding the publication of this paper.

\section{References}

[1] Gomez-Romero, P. and Sanchez, C. (Eds.) (2004) Functional Hybrid Materials. Wiley-VCH Verlag GmbH \& Co. KGaA, Weinheim.

[2] Novak, B.M. (1993) Hybrid Nanocomposite Materials-Between Inorganic Glasses and Organic Polymers. Advanced Materials, 5, 422-433.

https://doi.org/10.1002/adma.19930050603

[3] Corriu, R.J.P. (2000) Ceramics and Nanostructures from Molecular Precursors. Angewandte Chemie International Edition, 39, 1376-1398.

https://doi.org/10.1002/(SICI)1521-3773(20000417)39:8<1376::AID-ANIE1376>3.0. CO;2-S

[4] Paine, R.T. and Narula, C.K. (1990) Synthetic Routes to Boron Nitride. Chemical Reviews, 90, 73-91. https://doi.org/10.1021/cr00099a004

[5] Zheng, Z.Y., Cox, M. and Li, B. (2018) Surface Modification of Hexagonal Boron Nitride Nanomaterials: A Review. Journal of Materials Science, 53, 66-99. https://doi.org/10.1007/s10853-017-1472-0

[6] Joni, I.M., Balgis, R., Ogi, T., Iwaki, T. and Okuyama, K. (2011) Surface Functionalization for Dispersing and Stabilizing Hexagonal Boron Nitride Nanoparticle by Bead Milling. Colloids Surfaces A: Physicochemical and Engineering Aspects, 388, 49-58. https://doi.org/10.1016/j.colsurfa.2011.08.007

[7] Ciofani, G., Genchi, G.G., Liakos, I., Athanassiou, A., Dinucci, D., Chiellini, F. and Mattoli, V. (2012) A Simple Approach to Covalent Functionalization of Boron Nitride Nanotubes. Journal of Colloid and Interface Science, 374, 308-314. https://doi.org/10.1016/j.jcis.2012.01.049

[8] Sainsbury, T., Satti, A., May, P., Wang, Z., McGovern, I., Gun'ko, Y.K. and Coleman, J. (2012) Oxygen Radical Functionalization of Boron Nitride Nanosheets. Journal of the American Chemical Society, 134, 18758-18771. https://doi.org/10.1021/ja3080665

[9] Madakba, S., Sen, F., Kahraman, M.V. and Dumludag, F. (2014) Preparation, Characterization, Thermal, and Dielectric Properties of Polypyrrole/h-BN Nanocomposites. Advances in Polymer Technology, 1-8. https://doi.org/10.1002/adv.21438

[10] Furlotti, M., Caputo, R., Krumeich, F. and Nesper, R. (2015) Seamless Rim-Functionalization of h-BN with Silica-Experiment and Theoretical Modeling. Chemistry: A European Journal, 21, 7662-7667. https://doi.org/10.1002/chem.201500353

[11] Huang, Q., Bando, Y., Zhi, C., Golberg, D., Kurashima, K., Xu, F. and Gao, L. (2006) Chemical Peeling and Branching of Boron Nitride Nanotubes in Dimethyl Sulfoxide. Angewandte Chemie, 118, 2098-2101. https://doi.org/10.1002/ange.200504351

[12] Kisku, S.K. and Swain, S.K. (2012) Synthesis and Characterization of Chitosan/Boron Nitride Composites. Journal of the American Ceramic Society, 95, 2753 2757. https://doi.org/10.1111/j.1551-2916.2012.05140.x

[13] Huner, K., Ulutas, K., Deligoz, H., Sartinska, L. and Eren, T. (2017) ROMP-Based Boron Nitride Composites. Journal of Applied Polymer Science, 1-10. https://doi.org/10.1002/app.45658

[14] Kizilkaya, C., Mulazim, Y., Kahraman, M.V., Apohan, N.K. and Gungor, A. (2012) 
Synthesis and Characterization of Polyimide/Hexagonal Boron Nitride Composite. Journal of Applied Polymer Science, 124, 706-712. https://doi.org/10.1002/app.35054

[15] Chen, J., Chen, B., Li, J., Tong, X., Zhao, H. and Wang, L. (2017) Enhancement of Mechanical and Wear Resistance Performance in Hexagonal Boron Nitride-Reinforced Epoxy Nanocomposites. Polymer International, 66, 659-664.

https://doi.org/10.1002/pi.5296

[16] Huang, X., Zhi, C., Jiang, P., Golberg, D., Bando, Y. and Tanaka, T. (2013) Polyhedral Oligosilsesquioxane-Modified Boron Nitride Nanotube Based Epoxy Nanocomposites: An Ideal Dielectric Material with High Thermal Conductivity. Advanced Functional Materials, 23, 1824-1831.

https://doi.org/10.1002/adfm.201201824

[17] Ahmad, S., Sultan, A., Raza, W., Muneer, M. and Mohammad, F. (2016) Boron Nitride Based Polyaniline Nanocomposite: Preparation, Property, and Application. Journal of Applied Polymer Science, 1-9. https://doi.org/10.1002/app.43989

[18] Li, T.-L. and Hsu, S.L.-C. (2011) Preparation and Properties of Thermally Conductive Photosensitive Polyimide/Boron Nitride Nanocomposites. Journal of Applied Polymer Science, 121, 916-922. https://doi.org/10.1002/app.33631

[19] Qin, L., Li, G., Hou, J., Yu, X., Ding, H., Zhang, Q., Wang, N. and Qu, X. (2015) Preparation, Characterization, and Thermal Properties of Poly(methyl methacrylate)/Boron Nitride Composites by Bulk Polymerization. Polymer Composites, 1675-1684. https://doi.org/10.1002/pc.23078

[20] Kumar, V.N. and Srinivas, V.S.S. (2016) Enhancement of Thermal Stability of Natural Rubber Based Nano Composite Filled with Boron Nitride. Materials Today. Proceedings, 3, 3878-3881. https://doi.org/10.1016/j.matpr.2016.11.044

[21] Zhang, J., Wang, X.N., Yu, C.P., Li, Q.L., Li, Z., Li, C.W., Lu, H.F., Zhang, Q.C., Zhao, J.X., Hu, M. and Yao, Y.G. (2017) A Facile Method to Prepare Flexible Boron Nitride/Poly(vinyl alcohol) Composites with Enhanced Thermal Conductivity. Composites Science and Technology, 149, 41-47.

https://doi.org/10.1016/j.compscitech.2017.06.008

[22] Huang, X., Jiang, P. and Tanaka, T. (2011) A Review of Dielectric Polymer Composites with High Thermal Conductivity. IEEE Electrical Insulation Magazine, 27, 8-16. https://doi.org/10.1109/MEI.2011.5954064

[23] Li, G., Xiang, R., Geng, P., Liu, Z., He, L., Wang, N., Zhang, Q. and Qu, X. (2018) Surface Modification of Boron Nitride via Poly(dopamine) Coating and Preparation of Acrylonitrile-Butadiene-Styrene Copolymer/Boron Nitride Composites with Enhanced Thermal Conductivity. Polymers for Advanced Technologies, 29, 337-346. https://doi.org/10.1002/pat.4119

[24] Cao, Y., Deng, Q., Liu, Z., Shen, D., Wang, T., Huang, Q., Du, S., Jiang, N., Lin, C.-T. and Yu, J. (2017) Enhanced Thermal Properties of Poly(vinylidene fluoride) Composites with Ultrathin Nanosheets of MXene. RSC Advances, 7, 20494-20501. https://doi.org/10.1039/c7ra00184c

[25] Song, W.-L., Wang, P., Cao, L., Anderson, A., Meziani, M.J., Farr, A.J. and Sun, Y.-O. (2012) Polymer/Boron Nitride Nanocomposite Materials for Superior Thermal Transport Performance. Angewandte Chemie, 124, 6604-6607. https://doi.org/10.1002/ange.201201689

[26] Zhi, C., Bando, Y., Tang, C., Honda, S., Sato, K., Kuwahara, H. and Golberg, D. (2005) Characteristics of Boron Nitride Nanotube-Polyaniline Composites. Angewandte Chemie International Edition, 44, 7929-7932. 
https://doi.org/10.1002/anie.200502591

[27] Xiao, Q., Han, W.H., Yang, R.Q., You, Y., Wei, R.B. and Liu, X.B. (2017) Mechanical, Dielectric, and Thermal Properties of Polyarylene Ether Nitrile and Boron Nitride Nanosheets Composites. Polymer Composites, 1-8.

https://doi.org/10.1002/pc.24518

[28] Ayrilmis, N., Dudar, T., Kaymakci, A., Ozdemir, F. and Heon Kwon, J. (2014) Mechanical and Thermal Properties of Wood-Plastic Composites Reinforced with Hexagonal Boron Nitride. Polymer Composites, 194-200. https://doi.org/10.1002/pc.22650

[29] Gu, J., Zhang, Q., Dang, J. and Xie, C. (2012) Thermal Conductivity Epoxy Resin Composites Filled with Boron Nitride. Polymers for Advanced Technologies, 23, 1025-1028. https://doi.org/10.1002/pat.2063

[30] Zhu, Z.J., Wang, P.X., Lv, P., Xu, T.H., Zheng, J., Ma, C., Yu, K.H., Feng, W., Wei, W. and Chen, L.Y. (2017) Densely Packed Polymer/Boron Nitride Composite for superior Anisotropic Thermal Conductivity. Polymer Composites, 1-6. https://doi.org/10.1002/pc.24615

[31] Ji, T., Zhang, L.-Q., Wang, W.-C., Liu, Y., Zhang, X.-F. and Lu, Y.-L. (2012) Cold Plasma Modification of Boron Nitride Fillers and Its Effect on the Thermal Conductivity of Silicone Rubber/Boron Nitride Composites. Polymer Composites, 1473 1481. https://doi.org/10.1002/pc.22277

[32] Chen, B., Luan, D., Huang, J. and Zhang, J. (2015) Enhanced Thermal Conductivity and Wear Resistance of Polytetrafluoroethylene Composites through Boron Nitride and Zinc Oxide Hybrid Fillers. Journal of Applied Polymer Science, 1-7. https://doi.org/10.1002/app.42302

[33] He, Y.-M., Wang, Q.-Q., liu, W. and Liu, Y.-S. (2014) Functionalization of Boron Nitride Nanoparticles and Their Utilization in Epoxy Composites with Enhanced Thermal Conductivity. Physica Status Solidi A, 211, 677-684. https://doi.org/10.1002/pssa.201330305

[34] Wang, J.W., Li, H.R., Li, G.H., Liu, Z.X., Zhang, Q.X., Wang, N.Y. and Qu, X.W. (2017) Noncovalent Functionalization of Boron Nitride and Its Effect on the Thermal Conductivity of Polycarbonate Composites. Journal of Applied Polymer Science, 1-9. https://doi.org/10.1002/app.44978

[35] Ng, H.Y., Lu, X. and Lau, S.K. (2005) Thermal Conductivity of Boron Nitride-Filled Thermoplastics: Effect of Filler Characteristics and Composite Processing Conditions. Polymer Composites, 778-790. https://doi.org/10.1002/pc.20151

[36] Fang, H., Bai, S.-L. and Wong, C.P. (2016) "White Graphene"-Hexagonal Boron Nitride Based Polymeric Composites and Their Application in Thermal Management. Composites Communications, 2, 19-24.

https://doi.org/10.1016/j.coco.2016.10.002

[37] Jiang, Y., Shi, X., Feng, Y., Li, S., Zhou, X. and Xie, X. (2018) Enhanced Thermal Conductivity and Ideal Dielectric Properties of Epoxy Composites Containing Polymer Modified Hexagonal Boron Nitride. Composites Part A: Applied Science and Manufacturing, 107, 657-664. https://doi.org/10.1016/j.compositesa.2018.02.016

[38] Yang, N., Xu, C., Hou, J., Yao, Y., Zhang, Q., Grami, M.E., He, L., Wang, N. and $\mathrm{Qu}, \mathrm{X}$. (2016) Preparation and Properties of Thermally Conductive Polyimide/Boron Nitride Composites. RSC Advances, 6, 18279-18287. https://doi.org/10.1039/C6RA01084A

[39] Cakmakci, E., Kocyigit, C., Cakir, S., Durmus, A. and Kahraman, M.V. (2014) Preparation and Characterization of Thermally Conductive Thermoplastic Polyu- 
rethane/h-BN Nanocomposites. Polymer Composites, 530-538.

https://doi.org/10.1002/pc.22692

[40] Madakbas, S., Cakmakcil, E. and Kahraman, M.V. (2013) Preparation and Thermal Properties of Polyacrylonitrile/Hexagonal Boron Nitride Composites. Thermochimica Acta, 552, 1-4. https://doi.org/10.1016/j.tca.2012.11.011

[41] Gu, J., Meng, X., Tang, Y., Li, Y., Zhuang, Q. and Kong, J. (2017) Hexagonal Boron Nitride/Polymethyl-Vinyl Siloxane Rubber Dielectric Thermally Conductive Composites with Ideal Thermal Stabilities. Composites Part A: Applied Science and Manufacturing, 92, 27-32. https://doi.org/10.1016/j.compositesa.2016.11.002

[42] Gu, J.W., Lv, Z.Y., Wu, Y., Guo, Y.L., Tian, L.D., Qiu, H., Li, W.Z. and Zhang, Q.Y. (2017) Dielectric Thermally Conductive Boron Nitride/Polyimide Composites with Outstanding Thermal Stabilities via in-Situ Polymerization-Electrospinning-Hot Press Method. Composites Part A: Applied Science and Manufacturing, 94, 209216. https://doi.org/10.1016/j.compositesa.2016.12.014

[43] Gao, Y.W., Gu, A.J., Jiao, Y.C., Yang, Y.L., Liang, G.Z., Hu, J.-T., Yao, W. and Yuan, L. (2012) High-Performance Hexagonal Boron Nitride/Bismaleimide Composites with High Thermal Conductivity, Low Coefficient of Thermal Expansion, and Low Dielectric loss. Polymers for Advanced Technologies, 23, 919-928. https://doi.org/10.1002/pat.1992

[44] Yu, S.Z., Hing, P. and Hu, X. (2000) Dielectric Properties of Polystyrene-Aluminum-Nitride Composites. Journal of Applied Physics, 88, 398-404. https://doi.org/10.1063/1.373672

[45] Sun, J.J., Li, J.B., Sun, G.L., Zhang, B., Zhang, S.X. and Zhai, H.Z. (2002) Dielectric and Infrared Properties of Silicon Carbide Nanopowders. Ceramics International, 28, 741-745. https://doi.org/10.1016/S0272-8842(02)00037-8

[46] Çamurlu, H.E., Mathur, S., Arslan, O. and Akarsu, E. (2016) Modification of Hexagonal Boron Nitride Nanoparticles with Fluorosilane. Ceramics International, 42, 6312-6318. https://doi.org/10.1016/j.ceramint.2016.01.019

[47] Xu, G.F., Xu, W., Guan, A.R. and Cheng, X.N. (2007) Study on Electrical Properties of $\mathrm{ZrW}_{2} \mathrm{O}_{8} / \mathrm{e}-51$ Electronic Casting Composite Materials. Electron Components Mater., 26, 47-49.

[48] Zhi, C.Y., Terao, Y., Tang, C.C., Kuwahara, H. and Golberg, D. (2009) Chemically Activated Boron Nitride Nanotubes. Chemistry-An Asian Journal, 4, 1536-1540. https://doi.org/10.1002/asia.200900158

[49] Negrov, D.A. and Eremin, E.N. (2016) Structuring Peculiarities of Polytetrafluoroethylene Modified with Boron Nitride when Activated with Ultrasonic Exposure. Procedia Engineering, 152, 570-575. https://doi.org/10.1016/j.proeng.2016.07.657

[50] Wang, M., Jiao, Z., Chen, Y., Hou, X., Fu, L., Wu, Y., Li, S., Jiang, N. and Yu, J. (2018) Enhanced Thermal Conductivity of Poly(vinylidene fluoride)/Boron Nitride Nanosheet Composites at Low Filler Content. Composites Part A: Applied Science and Manufacturing, 109, 321-329.

https://doi.org/10.1016/j.compositesa.2018.03.023

[51] Ameduri, B. and Boutevin, B. (2004) Well-Architectured Fluoropolymers: Synthesis, Properties and Applications. Elsevier B. V., Amsterdam.

[52] Ameduri, B. and Sawada, H. (Eds.) (2016) Fluorinated Polymers: Volume 1, Synthesis, Properties, Processing and Simulation. RSC, Cambridge.

[53] Ameduri, B. and Sawada, H. (Eds.) (2016) Fluorinated Polymers: Volume 2, Applications. RSC, Cambridge.

[54] Sawada, H. (1996) Fluorinated Peroxides. Chemical Reviews, 96, 1779-1808. 
https://doi.org/10.1021/cr9411482

[55] Sawada, H. (2007) Synthesis of Self-Assembled Fluoroalkyl End-Capped Oligomeric Aggregates-Applications of These Aggregates to Fluorinated Oligomeric Nanocomposites. Progress in Polymer Science, 32, 509-533.

https://doi.org/10.1016/j.progpolymsci.2007.02.002

[56] Sawada, H. (2012) Preparation and Applications of Novel Fluoroalkyl End-Capped Oligomeric Nanocomposites. Polymer Chemistry, 3, 46-65. https://doi.org/10.1039/C1PY00325A

[57] Sawada, H. (2003) Novel Self-Assembled Molecular Aggregates Formed by Fluoroalkyl End-Capped Oligomers and Their Application. Journal of Fluorine Chemistry, 121, 111-130. https://doi.org/10.1016/S0022-1139(03)00040-X

[58] Oikawa, Y., Saito, T., Idomukai, S., Tanaka, T., Nishida, M. and Sawada, H. (2015) Preparation of Magnesium Carbonate Nanoparticles Encapsulated by Nanocomposite Material Derived from Fluoroalkyl End-Capped Vinyltrimethoxysilane Oligomer-Application to the Surface Modification of Glass and Poly(methyl methacrylate). Journal of Fluorine Chemistry, 177, 70-79. https://doi.org/10.1016/j.jfluchem.2015.02.003

[59] Saito, T., Tsushima, Y. and Sawada, H. (2015) Facile Creation of Superoleophobic and Superhydrophilic Surface by Using Fluoroalkyl End-Capped Vinyltrimethoxysilane Oligomer/Calcium Silicide Nanocomposites-Development of These Nanocomposites to Environmental Cyclical Type-Fluorine Recycle through Formation of Calcium Fluoride. Colloid and Polymer Science, 293, 65-73.

https://doi.org/10.1007/s00396-014-3387-5

[60] Sawada, H., Narumi, T., Kodama, S., Kamijo, M., Ebara, R., Sugiya, M. and Iwasaki, Y. (2007) A Fluoroalkyl End-Capped N-(1,1-Dimethyl-3-Oxobutyl)Acrylamide Oligomer/Silica Gel Nanocomposite with No Weight Loss Even at $800{ }^{\circ} \mathrm{C}$ Equal to an Original Silica Gel. Colloid and Polymer Science, 285, 977-983. https://doi.org/10.1007/s00396-007-1641-9

[61] Sawada, H., Shikauchi, Y., Kakehi, H., Katoh, Y. and Miura, M. (2007) Preparation and Applications of Novel Fluoroalkyl End-Capped Oligomers/Calcium Carbonate Nanocomposites. Colloid and Polymer Science, 285, 499-506. https://doi.org/10.1007/s00396-006-1566-8

[62] Tsuzuki-ishi, T. and Sawada, H. (2014) Facile One-Pot Preparation of Gold Nanoparticles in the Presence of Fluoroalkyl End-Capped Oligomers, Fluoroalkyl EndCapped Oligomers/Silica Nanocomposites, and Fluoroalkyl End-Capped Oligomers/Polyaniline Nanocomposites. Colloid and Polymer Science, 292, 2959-2969. https://doi.org/10.1007/s00396-014-3329-2

[63] Sawada, H., Tashima, T., Kakehi, H., Nishiyama, Y., Kikuchi, M., Miura, M., Sato, Y. and Isu, N. (2010) Fluoroalkyl End-Capped Oligomers Possessing Nonflammable and Flammable Characteristics in Silica Gel Matrices after Calcination at $800^{\circ} \mathrm{C}$ under Atmospheric Conditions. Polymer Journal, 42, 167-171.

https://doi.org/10.1038/pj.2009.316

[64] Sawada, H., Sasaki, A. and Sasazawa, K. (2009) Preparation of Size-Controlled Cross-Linked Fluoroalkyl End-Capped Oligomer/Gold Nanocomposites. Colloids and Surfaces A: Physicochemical and Engineering Aspects, 337, 57-60. https://doi.org/10.1016/j.colsurfa.2008.11.048

[65] Takashima, H., Iwaki, K., Takishita, K. and Sawada, H. (2009) Preparation and Applications of Novel Fluoroalkyl End-Capped Vinyltrimethoxysilane Oligomer/Hydroxyapatite Nanocomposites. Polymers for Advanced Technologies, 20, 887-891. https://doi.org/10.1002/pat.1320 
[66] Takashima, H., Iwaki, K., Furukuwa, R., Takishita, K. and Sawada, H. (2008) Journal of Colloid and Interface Science, 320, 436-444. https://doi.org/10.1016/j.jcis.2007.12.029

[67] Sawada, H., Takashima, H., Iwaki, K., Furukuwa, R. and Takishita, K. (2007) Preparation of Novel Fluoroalkyl End-Capped Oligomer/Hydroxyapatite Nanocomposites. Macromolecular Materials and Engineering, 292, 403-406. https://doi.org/10.1002/mame.200600462

[68] Sawada, H., Sasaki, A., Sasazawa, K., Toriba, K., Kakehi, H., Miura, M. and Isu, N. (2008) Preparation of Colloidal Stable Fluoroalkyl End-Capped Oligomer/Silver Nanocomposites-Application to the Surface Modification of Traditional Organic Polymers with These Nanocomposites. Polymers for Advanced Technologies, 19, 419-424. https://doi.org/10.1002/pat.1027

[69] Yoshioka, H., Ohnishi, K. and Sawada, H. (2007) Preparation of Fluoroalkyl End-Capped Oligomers/Magnetite Nanocomposites Possessing a Good Dispersibility and Stability. Journal of Fluorine Chemistry, 128, 1104-1111. https://doi.org/10.1016/j.jfluchem.2007.03.016

[70] Sawada, H., Furukuwa, R., Sasazawa, K., Mugisawa, M. and Ohnishi, K. (2007) Preparation of Novel Cross-Linked Fluoroalkyl End-Capped Adamantane Cooligomer/Copper Nanocomposites. European Polymer Journal, 43, 3258-3263. https://doi.org/10.1016/j.eurpolymj.2007.04.050

[71] Sasazawa, K., Hirayama, Y. and Sawada, H. (2009) Facile Preparation and Characterization of Novel Fluoroalkyl End-Capped Oligomer/Zinc Oxide Nanocomposites. Polymer International, 58, 177-182. https://doi.org/10.1002/pi.2511

[72] Mugisawa, M., Kasai, R. and Sawada, H. (2009) Cross-Linked Fluoroalkyl End-Capped Co-Oligomeric Nanoparticle-Encapsulated Fullerene-A New Approach to the Surface Modification of Traditional Organic Polymers with Fullerene-Containing Nanoparticles. Langmuir, 25, 415-421. https://doi.org/10.1021/la800875s

[73] Mugisawa, M., Ohnishi, K. and Sawada, H. (2007) Preparation of Novel Fluoroalkyl-End-Capped 2-Acrylamido-2-methylpropanesulfonic Acid Cooligomeric Nanoparticles Containing Adamantane Units Possessing a Lower Critical Solution Temperature Characteristic in Organic Media. Langmuir, 23, 5848-58851. https://doi.org/10.1021/la062060+

[74] Kijima, T., Javakhishvili, I., Jankova, K., Hvilsted, S., Kodama, S., Sugiya, M. and Sawada, H. (2012) Controlled Immobilization of Palladium Nanoparticles in Two Different Fluorinated Polymeric Aggregate Cores and Their Application in Catalysis. Colloid and Polymer Science, 290, 589-597. https://doi.org/10.1007/s00396-011-2567-9

[75] Sawada, E., Kakehi, H., Chounan, Y., Miura, M., Sato, Y., Isu, N. and Sawada, H. (2010) UV-Induced Switching Behavior of Novel Fluoroalkyl End-Capped Vinyltrimethoxysilane Oligomer/Titanium Oxide Nanocomposite between Superhydrophobicity and Superhydrophilicity with Good Oleophobicity. Composites Part B: Engineering, 41, 498-502. https://doi.org/10.1016/j.compositesb.2010.04.002

[76] Saito, T., Kakehi, H., Kato, Y., Miura, M., Isu, N. and Sawada, H. (2013) Fluoroalkyl End-Capped Oligomers Possessing Nonflammable Characteristic in Calcium Carbonate Nanocomposites. Polymers for Advanced Technologies, 24, 532-540. https://doi.org/10.1002/pat.3111

[77] Sawada, H., Kikuchi, M. and Nishida, M. (2011) Low Molecular Weight Aromatic Compounds Possessing a Nonflammable Characteristic in Fluoroalkyl End-Capped Acrylic Acid Oligomer/Silica Nanocomposite Matrices after Calcination at $800^{\circ} \mathrm{C}$ 
under Atmospheric Conditions. Journal of Polymer Science Part A: Polymer Chemistry, 49, 1070-1078. https://doi.org/10.1002/pola.24516

[78] Sawada, H., Matsuki, Y., Goto, Y., Kodama, S., Sugiya, M. and Nishiyama, Y. (2010) Preparation of Novel Fluoroalkyl End-Capped Trimethoxyvinylsilane Oligomeric Nanoparticle-Encapsulated Binaphthol: Encapsulated Binaphthol Remaining Thermally Stable Even at $800^{\circ}$ C. Bulletin of the Chemical Society of Japan, 83, 75-81. https://doi.org/10.1246/bcsj.20090204

[79] Mugisawa, M. and Sawada, H. (2008) Architecture of Linear Arrays of Fluorinated Co-Oligomeric Nanocomposite-Encapsulated Gold Nanoparticles: A New Approach to the Development of Gold Nanoparticles Possessing an Extremely Red-Shifted Absorption Characteristic. Langmuir, 24, 9215-9218. https://doi.org/10.1021/la8015035

[80] Guo, S., Yoshioka, H., Kakehi, H., Kato, Y., Miura, M., Isu, N., Ameduri, B. and Sawada, H. (2012) Fluoroalkyl End-Capped Vinyltrimethoxysilane Oligomer/Anatase Titanium Oxide Nanocomposites Possessing Photocatalytic Activity Even after Calcination at $1000^{\circ} \mathrm{C}$. Journal of Colloid and Interface Science, 387, 141-145. https://doi.org/10.1016/j.jcis.2012.08.005

[81] Guo, S., Yoshioka, H., Kato, Y., Kakehi, H., Miura, M., Isu, N., Manseri, A., Sawada, H. and Ameduri, B. (2014) Photocatalytic Activity of Vinylidene Fluoride-Containing Copolymers/Anatase Titanium Oxide/Silica Nanocomposites. European Polymer Journal, 58, 79-89. https://doi.org/10.1016/j.eurpolymj.2014.04.022

[82] Guo, S., Ogasawara, T., Saito, T., Kakehi, H., Kato, Y., Miura, M., Isu, N. and Sawada, H. (2013) Preparation and Photocatalytic Activity of Fluoroalkyl End-Capped Vinyltrimethoxysilane Oligomer/Anatase Titanium Oxide Nanocomposite-Encapsulated Low Molecular Weight Aromatic Compounds. Colloid and Polymer Science, 291, 2947-2957. https://doi.org/10.1007/s00396-013-3027-5

[83] Sawada, H., Gong, Y.F., Minoshima, Y., Matsumoto, T., Nakayama, M., Kosugi, M. and Migita, T. (1992) Synthesis and Surfactant Properties of Fluoroalkylated Oligomers Containing Carboxy Groups. Journal of the Chemical Society, Chemical Communications, 537-538. https://doi.org/10.1039/c39920000537

[84] Sawada, H., Yoshino, Y., Ikematsu, Y. and Kawase, T. (2000) Synthesis and Properties of Fluoro-Alkylated End-Capped Acrylamide Oligomers. European Polymer Journal, 36, 231-240. https://doi.org/10.1016/S0014-3057(99)00086-5

[85] Watanabe, K., Taniguchi, T. and Kaneda, H. (2004) Direct-Bandgap Properties and Evidence for Ultraviolet Lasing of Hexagonal Boron Nitride Single Crystal. Nature Materials, 3, 404-409. https://doi.org/10.1038/nmat1134

[86] Sawada, H., Yanagida, K., Inaba, Y., Sugiya, M., Kawase, T. and Tomita, T. (2001) Synthesis and Antibacterial Activity of Novel Fluoroalkyl End-Capped Cooligomers Containing Dimethyl(Octyl)Ammonium Segments. European Polymer Journal, 37, 1433-1439. https://doi.org/10.1016/S0014-3057(01)00005-2

[87] Kim, K., Kim, M., Hwang, Y. and Kim, J. (2014) Chemically Modified Boron Nitride-Epoxy Terminated Dimethylsiloxane Composite for Improving the Thermal Conductivity. Ceramics International, 40, 2047-2056.

https://doi.org/10.1016/j.ceramint.2013.07.117

[88] Sawada, H., Tashima, T. and Kodama, S. (2008) Preparation of a Variety of Fluoroalkyl End-Capped N-(1,1-Dimethyl-3-Oxobutyl)Acrylamide Oligomer/Silica Nanocomposites Possessing No Weight Loss Characteristic at $800^{\circ} \mathrm{C}$. Polymers for Advanced Technologies, 19, 739-747. https://doi.org/10.1002/pat.1050

[89] Sawada, H., Tashima, T., Nishiyama, Y., Kikuchi, M., Kostov, G., Goto, Y. and 
Ameduri, B. (2011) Iodine Transfer Terpolymerization of Vinylidene Fluoride, $\alpha$-Trifluoromethacrylic Acid and Hexafluoropropylene for Exceptional Thermostable Fluoropolymers/Silica Nanocomposites. Macromolecules, 44, 1114-1124. https://doi.org/10.1021/ma102532k

[90] Sawada, H., Kakehi, H., Tashima, T., Nishiyama, Y., Miura, M. and Isu, N. (2009) Fluoroalkyl End-Capped Oligomer Possessing a Nonflammable Characteristic in Silica Gel Matrices Even at $800^{\circ} \mathrm{C}$ under Atmospheric Conditions. Journal of Applied Polymer Science, 112, 3482-3487. https://doi.org/10.1002/app.29942

[91] Walsh, R. (1981) Bond Dissociation Energy Values in Silicon-Containing Compounds and Some of Their Implications. Accounts of Chemical Research, 14, 246252. https://doi.org/10.1021/ar00068a004

[92] Hildenbrnd, D.L. and Murad, E. (1965) Dissociation Energy of Boron Monofluoride from Mass-Spectrometric Studies. The Journal of Chemical Physics, 43, 1400-1403. https://doi.org/10.1063/1.1696932 